\title{
REGIONAL MULTIPLIER ANALYSIS: A DEMOMETRIC APPROACH
}

\author{
Jacques Ledent
}

RR $\cdot 78 \cdot 3$

March 1978

Research Reports provide the formal record of research conducted by the International Institute for Applied Systems Analysis. They are carefully reviewed before publication and represent, in the Institute"s best judgment, competent scientific work. Views or opinions expressed therein, however, do not necessarily reflect those of the National Member Organizations supporting the Institute or of the Institute itself.

International Institute for Applied Systems Analysis A - 2361 Laxenburg, Austria 
Jeanne Anderer, editor

Angela Marsland, composition

Martin Schobel, graphics

Printed by NOVOGRAPHIC

Maurer-Lange-Gassc 64

1238 Vienna

\section{Copyright (c) 1978 IIASA}

All rights reserved. No part of this publication may be reproduced or transmitted in any form or by any means, electronic or mechanical, including photocopy, recording, or any information storage or retrieval system, without permission in writing from the publisher. 
Interest in human settlement systems and policies has been a critical part of urban-related work at IIASA since its inception. Recently this interest has given rise to a concentrated research effort focusing on migration dynamics and settlement patterns. Four subtasks form the core of this research effort:

I The study of spatial population dynamics;

II The definition and elaboration of a new research area called demometrics and its application to migration analysis and spatial population forecasting;

III The design of migration and settlement policy models;

IV A comparative study of national migration and settlement patterns and policies.

This paper, the third in the demometrics series, illustrates the advantage of the demometric approach in conducting regional studies in areas experiencing rapid population growth. It shows that this approach yields more and better information than the traditional economic base approach.

Related papers in the demometrics series, and other publications of the migration and settlement study, are listed at the back of this report.

\author{
Andrei Rogers \\ Chairman \\ Human Settlements \\ and Services Area \\ March 1978
}





\section{Acknowledgments}

This work was initiated during my affiliation with the Division of Economic and Business Research, College of Business and Public Administration, University of Tucson, Arizona.

I wish to thank Andrei Rogers for his generous advice and helpful comments on a preliminary version which was presented at the 17th European Conference of the Regional Science Association, held in Krakow, Poland (August 23-26, 1977). Thanks also go to $T$ Kawashima and $R$. Dennis who made valuable suggestions. 



\begin{abstract}
This paper reports on the design and testing of an adequate framework for conducting regional multiplier studies in areas experiencing rapid population growth. It puts forward the demometric approach, one that applies econometric methods to the analysis of demoeconomic growth.

Two alternative models are proposed here. The first is an aggregate model presenting a demometric revision of the traditional economic base model. The second model, an enlarged version of the first, is characterized by a breakdown of economic activities into nine major sectors. Both models are fitted to data for the rapidly growing metropolitan area of Tucson, Arizona, USA. The models are then used to derive tentative impact and dynamic multipliers which substantiate the role of households as consumers and suppliers of labor in the development of Tucson SMSA.

The major finding is that, for the same level of resources, the second model yields better policy implications than the modified (and therefore also the traditional) economic base model.
\end{abstract}





\section{Contents}

THE DEMOMETRIC APPROACH IN A REGIONAL SETTING

MULTIPLIER ANALYSIS FOR TUCSON: A DEMOMETRIC REVISION OF THE ECONOMIC BASE APPROACH

The Traditional Economic Base Approach

Toward a Modified Economic Base Model for Tucson

Estimation of the Basic Sector in Tucson

The Modified Economic Base Model: Description and Construction

Impact and Dynamic Multipliers Obtained with the Modified Economic Base Model

MULTIPLIER ANALYSIS FOR TUCSON: A FULLER

A Brief Description of the Structure of the Demometric Model

Impact and Dynamic Multipliers Obtained with the

Demometric Model

CONCLUSION

APPENDIX 1: An Overview of Tucson's Development (1950-1975)

APPENDIX 2: Two-Stage Least Squares Parameter Estimates for the Demometric Model

REFERENCES 



\section{Regional Multiplier Analysis: A Demometric Approach}

In recent years, national as well as regional bodies of policy makers have made a serious effort to integrate regional data bases and analytical tools into the decisionmaking process. They have placed increasing demands on public agencies to complete regional multiplier analyses aimed at determining the economic and social implications of both national policies and regional projects.

Fundamental to these studies has been the attempt to identify the growth inducing sectors of regional economies and to understand how mechanisms of change take place and are transmitted to other regional sectors. A striking feature of these studies is their heavy reliance on a Keynesian demand approach to regional development that emphasizes the growth inducing role of firms while according only a cursory treatment to the role of households, (i.e., to demographic aspects). To be sure, most of the past multiplier analyses were related to areas in which population growth was relatively moderate and the role of demographic factors in regional development was somewhat difficult to identify. However, if such analyses had been performed for rapidly growing areas such as Arizona, Florida, or their subdivisions, the results would have certainly been erroneous and misleading for policymaking purposes.

Traditional approaches for conducting such analyses rely on either input-output models or economic base models. Generally versions of these models include the demand effects of population growth through household consumption, but neglect the alternate effects relating to the role of households as suppliers of labor. Because we expect that the larger the population growth, the more important these effects are, it is desirable to accord a better treatment to demographic variables, especially in cases of rapidly growing regions, in order to obtain a fuller picture of the mechanisms of regional development that lead to significant policy implications.

In the light of this, this paper begins by showing the inadequacy of the traditional economic base approach* for determining the consequences of government intervention in rapidly growing regions. It then proposes an amended economic base approach

*The use of an input-output model is here ruled out since this model requires large amounts of time and money inputs for the preparation of an input-output table. 
that presents a demometric revision of the dichotomy between basic and nonbasic sectors. A fuller demometric model that leads to the derivation of multipliers by broad industrial sectors (rather than of aggregate multipliers as in the modified economic base model) is outlined next. Both models are fitted to data for the rapidly growing metropolitan area of Tucson, Arizona (i.e., Tucson SMSA, a political unit also known as Pima County*) and relevant policy implications are discussed in both cases.

Before turning to the presentation and discussion of these alternative models, we briefly review the demometric philosophy that underlies this study.

\section{THE DEMOMETRIC APPROACH IN A REGIONAL SETTING}

The demometric approach is one that applies econometric methods to the analysis of the demoeconomic growth of a region.

Its principal objective is to establish quantitative statements regarding major demographic variables that explain the past behavior of such variables or that forecast (i.e., predict) their future behavior. (Rogers, 1976b)

Formally, the demometric approach calls for the construction of regional macro-demoeconomic models covering major components of regional growth (birth rates, migration rates, employment, output, population) but emphasizing the clearing of the local labor market which provides the connection between net-migration and labor force dynamics. Fundamentally, such models are characterized by the coupling of an economic model and a demographic model by means of two main linkages.

The former linkage appears in the form of a consumption function that demands the economy to produce a certain output for the population to consume. The latter linkage takes the form of a migration-labor force equilibrating model that views the demographic model as the supplier of labor and the economic model as the demander of labor. The two models operate recursively in developing forecasts of demographic and economic growth that are internally consistent. (Rogers 1976a)

The traditional economic base theory of regional development implies a demand view of economic growth that is an insufficient framework for such demoeconomic models. Indeed, the implementation of such models requires the availability of a more general theory of regional development. The recent literature, in fact,

* Both designations will be used interchangeably hereafter. 
displays a growing current of dissatisfaction with economic base theory as a suitable explanation for local development. Since Borts and stein (1964) first suggested the argument that households, rather than industries, determine the evolving spatial pattern of development through their roles as suppliers of labor, increasing consideration has been given to labor market conditions in regional studies. This has produced an important debate, namely, the identification of the sources of local growth as illustrated by the "chicken - or - egg" controversy in recent migration literature (Muth 1971, Mazek and Chang 1972).

What is the relationship between population growth (net inmigration) and employment growth? Are migration rates induced by differential rates of employment growth, as argued by the proponents of the aforementioned demand view of local development? Or does the path of causation go the other way around as advocated by the supporters of the alternative supply view? Clearly, the two paths of causation between migration and employment growth that these two polar views underline are not mutually exclusive but coexistent. Recent evidence, suggested by the findings of several empirical studies (Olvey 1972, Greenwood 1973, and Kalindaga 1974), indicates that migration and employment growth affect each other, with perhaps the dominant influence being that of migration on employment growth.

A large body of literature is available about labor force dynamics. Much of it is directed toward proving and disproving the "added worker" and "discouraged worker" hypotheses. However, a significant shift in the direction of research that could be profitable to the development of regional demometric models has recently occurred as researchers have started directing their attention to the job search process itself (Miron 1977).

To summarize, the recent literature in both migration analysis and regional labor force dynamics suggests a starting point for the construction of demoeconomic models of regional growth that could constitute an adequate framework for deriving meaningful policy implications. However, the development of such models remains difficult because of inadequate data on migration and labor force flows on a time series basis. To justify our effort we point out that the only accountable demographic data for Tucson available on a time series basis are aggregate data (i.e., they relate to the whole population); they include netmigrations, labor force totals, and unemployment rates. As this is clearly insufficient to formulate and test a definite connection between migration and labor force dynamics, it becomes necessary to redirect our strategy. Bearing in mind that a simple tool such as an economic base model strongly appeals to regional planners in spite of its weaknesses, it was decided to adopt a compromise between such an economic base model and the demometric model that one would ideally build for the Tucson SMSA. This led to the construction of two alternate models: 
- An amended version of the traditional economic base model, containing explicit labor force variables and introducing a demometric revision of the separation of the basic sector; and

- A fuller demometric model that takes advantage of what disaggregated data relating to employment, labor force and population are available for the Tucson SMSA.

\section{MULTIPLIER ANALYSIS FOR TUCSON: A DEMOMETRIC REVISION OF THE} ECONOMIC BASE APPROACH

To examine to what extent the economic base approach to regional analysis can be adapted to the case of a rapidly growing region, we first recall the highlights of the traditional economic base approach and then examine its limitations in order to uncover the sensitive elements that one has to modify to produce an amended version applicable to the Tucson SMSA.

\section{The Traditional Economic Base Approach}

In general terms, the economic base approach assumes that local economies operate on two scales:

- Transactions either take place internally, i.e., they involve the recycling of "nonbasic" money already in the local economy;

- Or they concern a product that is exported or purchased by an outsider, i.e., they require the importation of money from outside the considered area. The latter are called basic activities because the money that they bring into the local economy supposedly leads to the growth and expansion of economic activity.

The conceptual basis of the analysis assumes that the amount of activity in the basic sector determines the amount of activity in the nonbasic sector and thus in the whole economy. The general relationship between basic and nonbasic sectors can then be expressed as

$$
E_{S}=\alpha+\beta E_{b}
$$

in which $E_{b}$ and $E_{s}$ are, respectively, basic and nonbasic employment. Since total employment $\left(E_{t}\right)$ is given by the identity

$$
E_{t}=E_{b}+E_{s},
$$


we have

$$
E_{t}=\alpha+(1+\beta) E_{b}
$$

in which the coefficient $(1+\beta)$ defines the total employment that would be generated by the creation of one employment unit in the basic sector. This coefficient is generally referred to as the economic base multiplier. The economic base model is thus a simple framework describing the process of local development in terms of an assumed connection between economic sectors separated into two mutually exclusive sectors. Very often, an additional equation linking total population to total employment by some kind of "activity rate" permits a translation from the economic aspect of local development--embodied in the relationship linking basic and dependent sectors--to an alternative aspect, namely, population growth. Note that in such instances, population change, being merely a consequence of employment change, has no impact of its own on the overall development of the region.

This shortcoming can be remedied by introducing some feedback effects from population change to employment change through the explicit consideration of household consumption (Czamanski, 1964). In such instances, nonbasic employment is expressed as an increasing function of both basic employment and population

$$
E_{s}=\alpha+\beta E_{b}+\gamma P
$$

in which $P$ is the total population.

The model is completed by adding an equation in which $\mathrm{P}$ is made dependent on $\mathrm{E}_{t}$ :

$$
P=a+b E_{t}
$$

to express the assumption that labor supply (for which $\mathrm{P}$ constitutes a proxy) is always forthcoming as demanded by employment growth.

Solving for total employment and population as a function of basic employment yields

$$
\left\{\begin{array}{l}
E_{t}=\frac{\alpha+\gamma a}{1-b \gamma}+\frac{1+\beta}{1-b \gamma} E_{b} \\
P=\frac{a+b a}{1-b \gamma}+\frac{b(1+\beta)}{1-b \gamma} E_{b}
\end{array}\right.
$$


and gives the following multiplier with which to estimate the consequences of job creation in the basic sector:

$$
\begin{aligned}
& \frac{\Delta E_{t}}{\Delta E_{b}}=\frac{1+\beta}{1-b \gamma} \\
& \frac{\Delta P}{\Delta E_{b}}=\frac{b(1+\beta)}{1-b \gamma} .
\end{aligned}
$$

The economic base approach involves many practical and theoretical problems. From a practical point of view, a prerequisite to the use of the economic base approach is the identification and measurement of the economic base sector. Such a task, however, generally cannot be performed with commonly available data. If available resources permit, a special survey can be carried out to separate the basic and dependent segments in the major sectors. Otherwise, the identification of the basic sector must be made using nonsurvey methods.

From a theoretical point of view, the questions raised can be classified into two broad categories. The first group includes problems which stem from the simple formulation of the traditional economic base model and which can perhaps be amended when dealing with a fast-growing area namely, the focus on a demand-oriented view of regional growth, and the static character of the relationships between employment and population variables. The second category of problems consists of all the questions inherent to the economic base concept itself; questions that can be removed only by adopting an alternative approach.*

\section{Toward a Modified Economic Base Model for Tucson}

The use of the above economic base model to calculate multipliers for the Tucson SMSA is likely to be insufficient, if not misleading. In view of the recent evolution of economic and demographic growth in that area,** it is clear that the additional jobs that could be created as a consequence of government intervention would not go only to residents but also to new inmigrants attracted by these new prospects. Thus, the creation of additional basic jobs would bring to Tucson an additional population (and thus a labor force) that could exceed, at least in the short term, the population change that would result from the application of formula (9). This would undoubtedly have an impact on the area's labor market and thus affect its development.

*These problems are examined in the beginning of the second part of this paper.

**An overview of Tucson's development over the last quarter of a century appears in Appendix 1. 
Dealing with a region in which a majority of additional jobs are likely to be taken by nonresidents therefore requires a modification of the demand oriented view of regional growth in at least two ways. One consists of assessing the effect of a large pool of readily available workers on the growth of labor demand; while the second relates to including the consequences of relative shortages and surpluses of labor on the expectations of workers.

In view of the constraint created by the existence of only two sectors in the regional economy (basic and nonbasic), the first improvement can be accommodated by proposing a method for identifying and measuring the basic sector in Tucson and allowing for a consideration of the role of households as suppliers of labor. The second improvement, on the other hand, which leads to a better consideration of the response of the Tucson and the US populations to changes in economic opportunities in Tucson, can be handled by amending the structure of the traditional economic base model. For that purpose, it is suggested that the role of households as suppliers of labor be explicitly introduced by means of labor force variables (labor force participation and unemployment rates) and that an alternative to population equation (5) be proposed to explicitly show the consequences of changes in employment opportunities on population change. Moreover, since some of these consequences are expected to be not contemporaneous but lagging, the resulting equation is likely to introduce a dynamic element that responds to another of the criticisms directed at the traditional economic base.

The improvements envisioned for the application of the economic base model approach to the case of the Tucson SMSA leads to the construction of a model that is slightly more complicated than the traditional economic base model and appears as a smallscale dynamic econometric model (or demometric model, since several demographic variables are to be explicitly introduced). Fortunately, such a structural change permits one to derive meaningful multipliers with a time dimension. These are labelled "impact and dynamic multipliers"* and are obtained by a simple matrix calculus in the case of a linear model or by comparing a "control" solution of the model with the "perturbed" solutions in the case of a nonlinear model (Goldberger 1959). Before turning to the description of the structure of our model, we first attempt to estimate the basic sector of Tucson so as to implement the first suggested modification of the traditional economic base model.

\footnotetext{
* Impact multipliers reflect the instantaneous effects of a change in an exogenous variable on an endogenous variable, whereas dynamic multipliers relate to the delayed effects that would result if the initial shock to the system, imposed by the exogenous change in the exogenous variable, is sustained over time.
} 
Estimation of the Basic sector in Tucson

The two most popular methods for estimating the basic sector of a regional economy are the location quotients method and the minimum requirements method. Both have serious drawbacks because of their restrictive assumptions regarding what constitutes basic activity. Moreover they do not lend themselves to a simple modification to account for the specific character of Tucson's development. We present here an alternative econometric method based on an extension of an idea first proposed by Mathur and Rosen (1972).

\section{The Mathur/Rosen Method}

The Mathur/Rosen method hypothesizes that in each economic sector of a regional economy, that part of employment which is basic is sensitive to changes in total employment in the nation (NEMP). The procedure used to separate basic and nonbasic employment is as follows. Assume that

$$
E_{i}=\beta_{i 0}+\beta_{i 1} \text { NEMP }+e_{i}
$$

where

$$
\begin{aligned}
& E_{i} \text { is the employment in the } i^{\text {th }} \text { industry, and } \\
& e_{i} \text { is the stochastic disturbance term. }
\end{aligned}
$$

Applying OLS (ordinary least squares) estimators, one can obtain a regression equation:

$$
\hat{E}_{i}=\hat{\beta}_{i 0}+\hat{\beta}_{i 1} \text { NEMP }
$$

Properties of the estimators are such that

$$
\bar{E}_{i}=\hat{\beta}_{i 0}+\hat{B}_{i 1} \overline{\mathrm{NEMP}} \text {, }
$$

where $\overline{\mathrm{E}}_{i}$ and $\overline{\mathrm{NEMP}}$ are the averages (means) of $\mathrm{E}_{i}$ and NEMP, respectively, over the observed period.

Mathur and Rosen assume that the ratio of basic employment in the region's industry to total employment in the nation remains constant over the entire period, and they define the 
proportion of basic employment in industry i to be

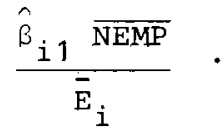

A careful examination of this procedure reveals two serious problems :

1. The assumption of a constant ratio of basic to total employment is unrealistic in view of the processes of regional growth that typically occur in market economies;

2. The percentage of nonbasic employment in the $i^{\text {th }}$ industry is then equal to

$$
1-\hat{\beta}_{i 1} \frac{\overline{\text { NEMP }}}{\overline{\bar{E}_{i}}}=\frac{\hat{\beta}_{i 0}}{\bar{E}_{i}} \text {. }
$$

Thus the separation of employment into its basic and dependent components for each industrial sector depends on the sign and magnitude of $\hat{\beta}_{i 0}$. The Mathur/Rosen method does not ensure that $\hat{\beta}_{i 0}$ will be positive and less than $\bar{E}_{i} ;$ as a matter of fact, in the case of local industries in which employment grows faster than national total employment, it can be shown that the intercept of the above regression tends to be negative. Mathur and Rosen then recommend the plotting of $\ell n E_{i}$ (instead of $E_{i}$ ) against NEMP. However the intercept would tend to be positive only when ln $E_{i}$ does not grow faster than NEMP.

The method proposed by Mathur and Rosen produces a separation of economic sectors that simply reflects the relative growth rates in the industry-specific employments of the local economy and national employment in all sectors. Also, the actual figures that it yields depend heavily on the choice of the equations fitted to the data (e.g., whether they are linear or nonlinear). Consequently, such a separation into basic and nonbasic sectors can produce arbitrary results and casts some doubts about the method's robustness. Nevertheless, this method offers a starting point for an improved econometric method for identifying the basic sector. 


\section{An Extension of the Mathur/Rosen Method}

Let us relax the assumption of a constant ratio of basic to total employment and attempt to incorporate the above observation that the multiplier process is the reduced form of a process that involves an active participation of households through demand and supply effects.

An obvious candidate to replace the typical Mathur/Rosen stochastic equation is

$$
E_{i}=\beta_{i 0}+\beta_{i 1} \text { NEMP }+\beta_{i 2} P O P+\beta_{i 3} \text { LFPR }+e_{i}
$$

where POP is the local population (a mixed demand/supply effect), and LFPR is the local labor force participation rate (supply factor).

To avoid the difficulties encountered by Mathur and Rosen with the intercept, we focus on changes in employment rather than on levels and define the percentage of employment change that is basic in nature as

$$
\frac{\hat{B}_{i 1}[\operatorname{NEMP}(t+k)-\operatorname{NEMP}(t)]}{\hat{E}_{i}(t+k)-\hat{E}_{i}(t)} \times 100
$$

where

$$
\hat{E}_{i}(y)=\hat{\beta}_{i 0}+\hat{\beta}_{i 1} \operatorname{NEMP}(y)+\hat{\beta}_{i 2} \operatorname{POP}(y)+\hat{\beta}_{i 3} \operatorname{LFPR}(y),
$$

and $t$ and $t+k$ are the first and the last years of the fitting period respectively.

If the coefficient of one of the regional variables is not statistically significant, the corresponding variable is discarded and a new regression is run without it. If the coefficient of LFPR is not significant in (11) the substitute form for the regression equation is

$$
\mathrm{E}_{i}=\beta_{i 0}+\beta_{i 1} \mathrm{NEMP}+\beta_{i 2} \text { POP }+e_{i} \text {, }
$$

*The estimation of the corresponding regression equation is expected to yield three positive coefficients: $\hat{\beta}_{i 1}, \hat{\beta}_{i 2}$, and $\hat{\beta}_{i 3}$. 
and the percentage of employment change which is basic in nature would be given by the same formula as above in which $\hat{E}_{i}(y)$ would now be

$$
\hat{\beta}_{i 0}+\hat{\beta}_{i 1} \operatorname{NEMP}(y)+\hat{\beta}_{i 2} \operatorname{POP}(y) \text {. }
$$

Alternatively, if the coefficient of POP is not significant in (11) the substitute stochastic equation is

$$
E_{i}=\beta_{i 0}+\beta_{i 1} \text { NEMP }+\beta_{i 2} \text { LFW }
$$

where LFW is the total local labor force. The percentage of employment change that is basic would be obtained in a similar way.

Finally, if $\hat{\beta}_{i 1}$ (the coefficient of the national employment variable) fails to be significant in either of the above formulations, then the employment change is regarded as nonbasic.

If neither of the coefficients of LFPR and POP is significant, or if $\hat{\beta}_{i 2}$ is not significant in (11) through (13) ( $\hat{\beta}_{i 1}$ being significant), then one would simply use

$$
E_{i}=\beta_{i 0}+\beta_{i 1} \operatorname{NEMP}+e_{i}
$$

and qualify the whole employment change as basic if the $\hat{\beta}_{i 1}$ obtained is significant, and nonbasic otherwise.

The above method has been applied to the Tucson economy, for which annual employment data were available for the period 1956-75. In the case of the service sector, for example, we have obtained (by applying the OLS estimation with correction for first-order auto correlation) the following regression equation:*

$$
\begin{aligned}
& \text { SERV }=-30.340+0.130 \times 10^{3} \mathrm{NEMP}+0.059 \mathrm{POP}+53.892 \mathrm{LFPR} \\
& \begin{array}{llll}
(-23.403)(4.4516) & (16.436) & (14.571)
\end{array} \\
& \text { Period: } 1956-75 \text { Mean }=16.679 \quad \rho=-.089 \\
& \mathrm{R}^{2}=.999 \quad \overline{\mathrm{R}}^{2}=.999 \quad \mathrm{SE}=.253 \quad \mathrm{DW}=1.298 \quad \mathrm{~F}(3,14)=4296.0 .
\end{aligned}
$$

\footnotetext{
*The statistics between parentheses located just under each regression coefficient are the corresponding t-statistics. The employment figures are expressed in thousands.
} 
Using this equation, it can be established that only 16.7 percent of the variations in service employment are explained by variations in the national employment variable. This is consistent with the a priori expectation that the service industry is a nonbasic oriented industry. Table 1 shows the results calculated using our approach and indicates that industrial employment changes in Tucson SMSA may be classified as being:

- Totally basic in manufacturing;

- Partially basic in mining, transportation/communication, trade, services, and various levels of government; and

- Completely dependent (nonbasic) in agriculture, construction, finance, and real estate.

Table 1. Percentages of employment change that are basic, according to sectors: Tucson SMSA 1956-1975.

\begin{tabular}{|c|c|c|c|c|c|}
\hline Sector & Percentage & $\begin{array}{l}\text { Equation } \\
\text { Format* }\end{array}$ & Sector & Percentage & $\begin{array}{l}\text { Equation } \\
\text { Format* }\end{array}$ \\
\hline Agriculture & 0.0 & (14) & Trade & 19.6 & (11) \\
\hline Mining & 57.4 & (12) & $\begin{array}{l}\text { Finance/Real } \\
\text { Estate }\end{array}$ & 0.0 & $(14)$ \\
\hline Manufacturing & 100.0 & (14) & Service & 16.7 & (11) \\
\hline Construction & 0.0 & (14) & $\begin{array}{c}\text { Local/State } \\
\text { Government }\end{array}$ & 22.3 & (13) \\
\hline $\begin{array}{l}\text { Transportation/ } \\
\text { Communication }\end{array}$ & 33.0 & (12) & $\begin{array}{l}\text { Federal } \\
\text { government }\end{array}$ & 57.6 & (13) \\
\hline
\end{tabular}

In general, these figures confirm a priori expectations about the basic or the nonbasic character of each industry. An exception to this appears in agriculture, probably because in the Tucson SMSA this sector employs a small number of workers that has remained approximately constant over the period of observation.

The Modified Economic Base Model: Description and Construction

We now turn to the presentation of our model, which consists of eight equations (four identities and four stochastic equations, estimated by regression analysis from time series data for the

*The equation formats denote the equations used to determine the percentages of employment change which are linked to basic activities. 
Tucson SMSA) and includes eleven variables, three of which (change in basic employment, national unemployment rate, and a time trend) are necessarily exogenous.

Equation 1 in Table 2 accounts for variations in total employment change by relating these to the two independent variables: employment change in the basic sector, and the net migration level. The coefficients of both these variables should be positive.*

Population growth has been broken down into its main components of change. Net migration (equation 2 in Table 2) is tied to employment change and to the difference in the economic conditions that prevail at both the local and national levels as reflected by their differential unemployment rates. (See Figure 1 for a comparison of the evolution of these variables.) Note the one year lag attached to the local and national unemployment rates.

The employment change variable in that equation is expected to be positively correlated with the dependent variable (the larger the job opportunities, the larger the attraction of Tucson for migrants). The local unemployment rate is expected to have a negative coefficient, and the national unemployment rate should have a positive coefficient.

Natural increase in population (equation 3 in Table 2) is described by a simple regression equation in which a time trend (expected to be negative) should express the observed decreasing tendency of Tucson's natural rate of increase.**

The introduction of labor market related variables into the model and characterizing the interaction of population and employment growth mainly through the impact of the labor market surplus (unemployment) raises a consistency problem that can be summarized with the aid of Figure 2 below.

Clearly, no model can independently predict all five variables in the above diagram since these variables are related by two definitional relationships: those defining labor force participation rates and unemployment rates. Inevitably, this means that two of the five variables have to be calculated as residuals.

* Note that both employment change variables are contemporaneous (i.e., they express changes in employment observed in two successive years $t-1$ and $t)$. The net migration variable is an estimate of this population component of change between July 1 in year $t-1$ and July 1 in year $t$. Thus no attempt is made to test for the occurrence of delays in the responses of economic agents to changes in economic conditions.

**Such a treatment is justified by the greater importance of structural changes $v$ is a vis changes across the business cycle in explaining fertility decline in the recent history of the USA. 
Table 2. Modified economic base model of the Tucson SMSA.* Regression equations**

1 DEMPW $=1.857$ DBA.SIC +0.219 NETMIG

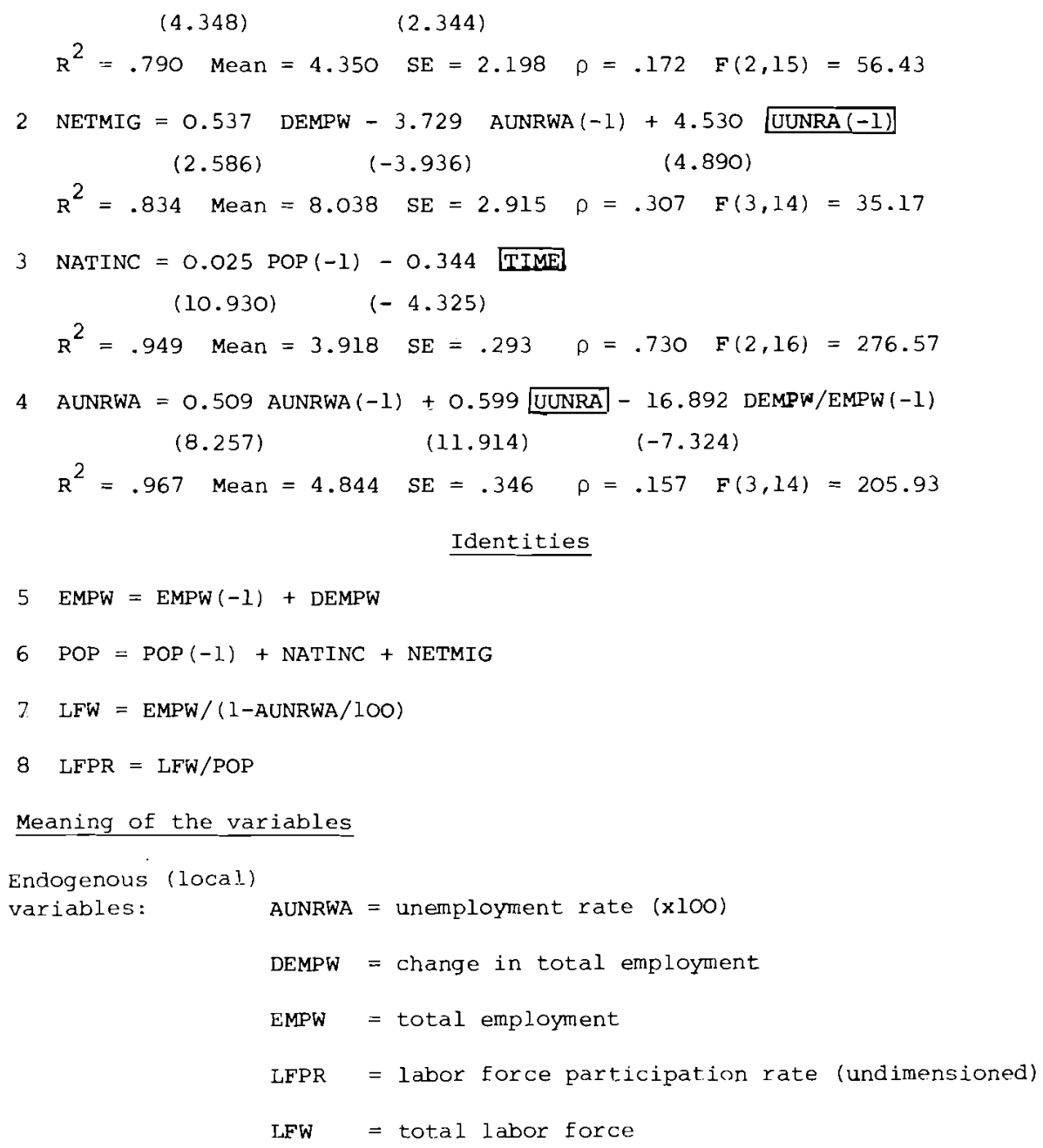

*All figures are expressed in thousands unless otherwise indicated. **Statistics between parentheses are the t- statistics. Exogenous variables appear in rectangular boxes. 
Table 2. (cont'd)

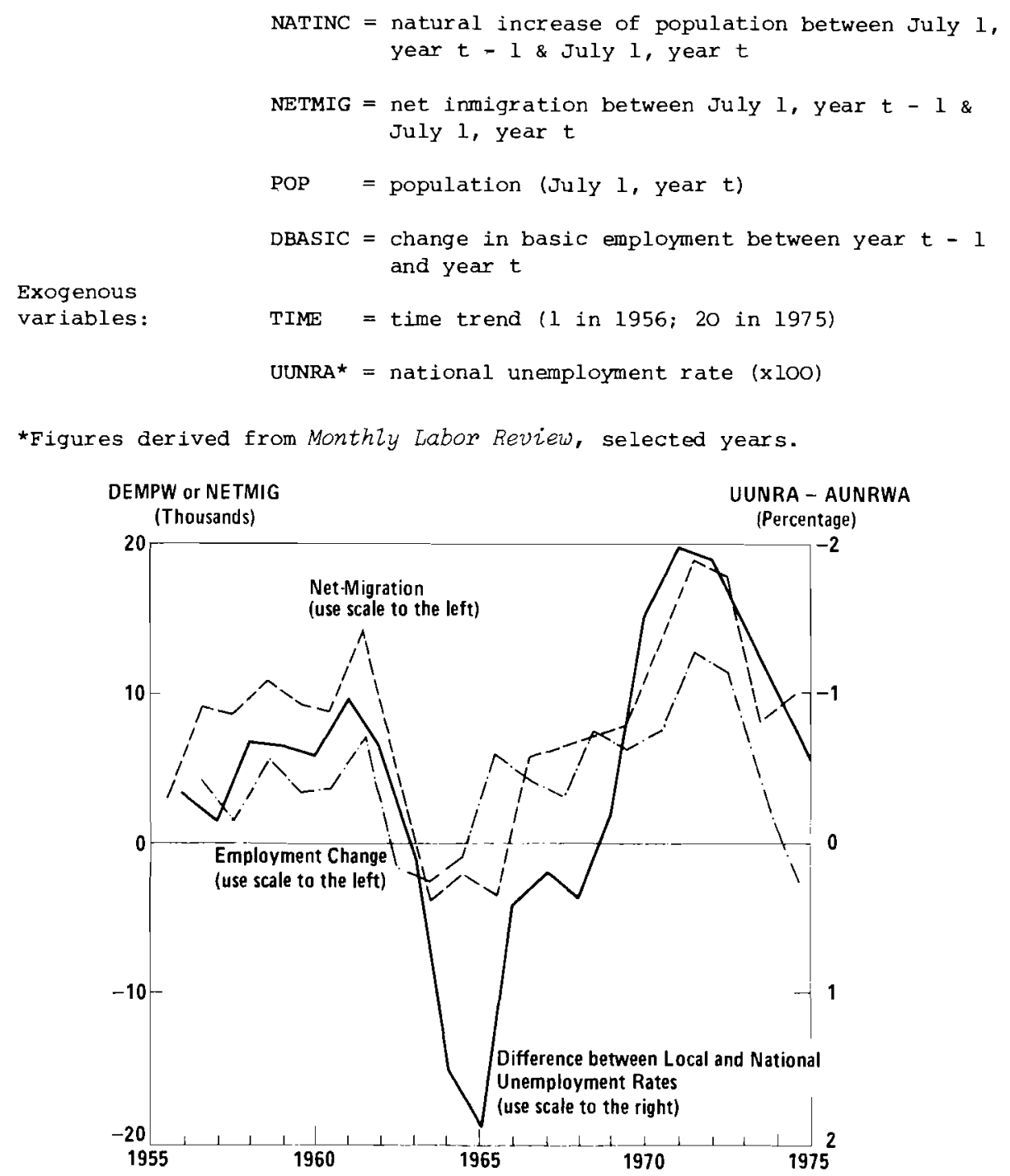

Figure 1. Comparison between net migration, employment change, and differences between local and national unemployment rates. Tucson 1956-1975.

Source: Employment change and local unemployment rate: Arizona Department of Economic Security, 1976.

Net migration: derived by author from data published by Arizona

Department of Economic Security, 1976.

National unemployment rate: Monthly Labor Review, selected years. 


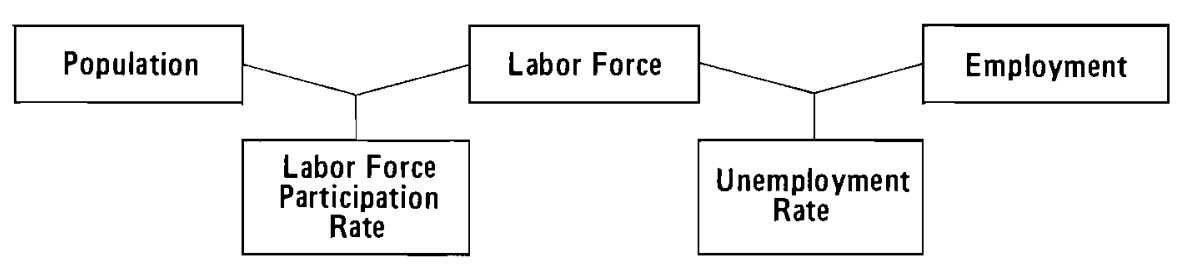

Figure 2. The basic relationship between the main demographic and economic variables in a consistent demoeconomic model.

Perhaps the obvious candidates for residuals are the unemployment rate and the labor force participation rate since they are not primary variables. However, when they are calculated as residuals, they often take on absurd values, especially the unemployment rates.* In this sense, the population and employment variables might not be consistent.

In general, this consistency problem requires one to choose as dependent variables three of the five variables listed in Figure 2. In our case, the variable most likely to create problems is the unemployment rate, population and employment having been chcsen as primary variables. This means that total labor force and the labor force participation rate are to be residuals. The values of these residuals might not be plausible relative to obvious trends in labor force partcipation, but it is likely that the discrepancy would be smaller than for any other choice of the dependent variables.

The fourth stochastic equation (in Table 2) expresses the variations of the local unemployment rate, and relates these to variations in variables such as national unemployment, relative increase in total employment, and a lagged value of the dependent variable.**

The model is completed by adding four identities. The first two show that the current levels of the population and employment variables are obtained by adding their current components-of-change levels to their previous-year levels. The last two give the two residual variables: labor force and labor force participation rate.

*For example, if one predicts labor force with a one percent error (overestimation) and employment with also a one percent error (underestimation) the error made on the forecast of the corresponding unemployment rate is forty percent (if the unemployment rate is equal to five percent).

**Such a specification of the unemployment equation may be found in Chang (1976). 
The stochastic equations of the model have been fitted to annual data for the period 1956-1975 using both ordinary leastsquares (OLS) and two-stage least squares (2SLS). Noting that they lead to similar estimates we report here only the 2SLs estimates. In theory, these are the only appropriate ones in light of the simultaneous nature of the model.

The actual fits of the employment change and net migration equations show high values for the t-statistics* (see Table 2), thus indicating a large significance of the independent variables (which, moreover, have the expected sign in all circumstances). However, the overall performance of these equations in terms of their coefficients of determination is less satisfactory. This is not surprising when one considers the volatile character of the net migration variable and of the aggregate nature of the relationship between basic and nonbasic sectors.

Having completed the estimation stage, the next step in the construction of the model consists of carrying out the simulation. Although the model is nonlinear, the use of a Gauss-seidel iterative method is not necessary because the final form of the model can be calculated.** This permits one to simulate the model over the sample period and then to compare actual versus predicted values of the endogenous variables. The precision obtained is judged sufficiently accurate given the aggregate nature of the model.

It is possible to compare a perturbed simulation of the model, obtained after an exogenous increase in basic employment, with the base-run simulation and to derive aggregate impact and dynamic multipliers.

Impact and Dynamic Multipliers Obtained with the Modified Economic Base Model

Table 3 shows impact and dynamic multipliers (derived by simulation procedures) associated with the creation of jobs in the basic sector in 1958, 1967, and 1974, respectively. It suggests the following observations:

*When estimating the four stochastic equations of the model, the intercepts appeared to have very low t-statistics. The corresponding equations were then refitted with zero intercepts. These versions were finally retained because they improved the overall performance of the regression equations while modifying the parameter estimates only slightly.

**This is so because the nonlinear variables (labor force and labor force participation rate) appear separately from the main block, and in this main block, the dependent variables are linear functions of the current independent variables. 
Table 3. Impact and dynamic multipliers from the modified economic base model.

\begin{tabular}{|c|c|c|c|c|}
\hline Multiplier & $\begin{array}{c}\text { Year of } \\
\text { Measurement }\end{array}$ & $\begin{array}{l}\text { Creat } \\
\mathrm{T}=1958\end{array}$ & $\begin{array}{l}\text { Basic J } \\
\mathrm{T}=1967\end{array}$ & $\begin{array}{l}\text { Year } \\
\mathrm{T}=1974\end{array}$ \\
\hline$\frac{\triangle \mathrm{EMPW}}{\triangle \mathrm{BASIC}}$ & $\begin{array}{c}\mathrm{T} \\
\mathrm{T}+2 \\
\mathrm{~T}+4\end{array}$ & $\begin{array}{l}2.10 \\
2.85 \\
3.16\end{array}$ & $\begin{array}{l}2.10 \\
2.68 \\
2.87\end{array}$ & $\begin{array}{l}2.10 \\
2.46 \\
2.57\end{array}$ \\
\hline$\frac{\triangle \mathrm{NETMIG}}{\triangle \mathrm{BASIC}}$ & $\begin{array}{c}\mathrm{T} \\
\mathrm{T}+2 \\
\mathrm{~T}+4\end{array}$ & $\begin{array}{l}1.13 \\
4.53 \\
5.95\end{array}$ & $\begin{array}{l}1.13 \\
3.76 \\
4.64\end{array}$ & $\begin{array}{l}1.13 \\
2.74 \\
3.25\end{array}$ \\
\hline$\frac{\triangle \mathrm{POP}}{\triangle \mathrm{BASIC}}$ & $\begin{array}{c}T \\
T+2 \\
T+4\end{array}$ & $\begin{array}{l}1.13 \\
4.63 \\
6.31\end{array}$ & $\begin{array}{l}1.13 \\
3.85 \\
4.95\end{array}$ & $\begin{array}{l}1.13 \\
2.82 \\
3.48\end{array}$ \\
\hline$\frac{\triangle A U N R W A}{\triangle B A S I C}(8)$ & $\begin{array}{c}\mathrm{T} \\
\mathrm{T}+2 \\
\mathrm{~T}+4\end{array}$ & $\begin{array}{l}-.49 \\
-.21 \\
-.04\end{array}$ & $\begin{array}{l}-.38 \\
-.14 \\
-.02\end{array}$ & $\begin{array}{l}-.24 \\
-.08 \\
-.02\end{array}$ \\
\hline$\frac{\triangle \mathrm{LFPR}}{\triangle \mathrm{BASIC}}$ & $\begin{array}{c}\mathrm{T} \\
\mathrm{T}+2 \\
\mathrm{~T}+4\end{array}$ & $\begin{array}{l}.62 \\
.50 \\
.42\end{array}$ & $\begin{array}{l}.44 \\
.40 \\
.35\end{array}$ & $\begin{array}{l}.31 \\
.31 \\
.29\end{array}$ \\
\hline
\end{tabular}

- The consequences on total employment and population seem to be relatively high. For example, the corresponding five-year dynamic multipliers have maximum values of 3.16 and 5.95, respectively, for an exogenous change in the basic sector in 1958 .

- Comparisons of the impact multipliers with the five-year dynamic multipliers show that the delayed effects of job creation are relatively moderate and tend to diminish as the size of the local economy increases. For example, the economic base multiplier $\frac{\triangle E M P W}{\triangle B A S \overline{I C}}$ decreases from 3.16 for job creation in 1958 to 2.57 for job creation in 1974 .

- A comparison of the dynamic population and employment multipliers indicates that the delayed effects of job creation are proportionally higher in the case of population than in the case of employment. 
- As expected, the effect of additional jobs in the basic sectors is to diminish the unemployment rate and to increase the labor force participation rate, However, if the increase in the labor force participation rate (as indicated by impact multipliers) is maintained well over the next few years (as indicated by the dynamic multipliers), the downward pressure on the unemployment rate tends to decline as the dynamic multipliers for this variable tend toward zero.*

- Comparing the values of the multipliers for different years of occurrence in job creation, we observe that a) impact multipliers remain the same because of the structure of the model (simultaneous links are specified with linear equations having constant coefficients); and b) the magnitude of the dynamic multipliers displays a tendency to decrease as the occurrence of additional employment is retarded. This last finding is not surprising. It makes sense that the marginal effect of a given increase in basic employment diminishes as the size of Tucson increases. But which characteristics of the model account for such a result? A careful examination of the interaction between equations reveals that the specification of the unemployment rate equation is mainly responsible for this result. Relative employment change is a determining variable with regard to the employment rate.

\title{
MULTIPLIER ANALYSIS FOR TUCSON: A FULLER DEMOMETRIC APPROACH
}

\begin{abstract}
Although the preceding aggregate model has included some corrective elements not generally found in classic economic base theory, its use for policy analysis remains questionable for reasons inherent in the nature of the dichotomy between basic and dependent sectors. The vagueness of the notion of the basic sector leaves room for a broad interpretation and this does not facilitate transferring the macro point of view of economic base identification to the micro level. Some jobs are clearly basic (production of steel shipped outside the local area); others are clearly nonbasic (teaching in a locally-oriented primary school). In many instances, however, classifying a job as basic or nonbasic is impossible.
\end{abstract}

Another question raised by the economic base concept is the aggregative nature of the associated multipliers which express an average of the multiplier effects induced by changes in the basic

\footnotetext{
* This result only occurs when job expansion takes place in the later years of the sample period. For basic employment creation in the earlier years, the unemployment rate multipliers become positive and tend to diverge. We have here a case of nonconverging dynamic effects.
} 
sector as a whole. As a consequence, the multipliers may not be applicable to a particular industry and thus may result in an inadequate estimation of the effects generated by the construction of a given factory.

It is therefore desirable to abandon the basic/nonbasic dichotomy and to adopt an alternative approach which is suggested by the findings of the demometric identification of the basic sector in Tucson. Since this identification required the establishment of regression equations linking sectoral employment growth and population growth in the Tucson SMSA (the results of which were then used as exogenous information in a small-scale demometric model), it appears rational to make these equations an endogenous part of the model.

\section{A Brief Description of the Structure of the Demometric Model}

Our demometric model contains two main parts: an employment part and a demographic part. The employment part consists of an exogenous sector, agriculture, and nine endogenous sectors: mining, manufacturing, construction, transportation/communication, trade, finance and real estate, services/government and selfemployed.

In accordance with the demometric philosophy, the actual equations acknowledge that external markets are not the only sources of growth, and that population growth through its demand and supply effects is a complementary growth factor.

The demographic part of the model determines actual births, deaths, and net migrants to obtain the new population every year. Although a disaggregation paralleling that of the economic side is highly desirable in determining these components of change, it cannot be implemented owing to the virtual nonexistence of time series data on migration. This is unfortunate since the decomposition of net migration into its gross components (inmigration and outmigration) would have brought in useful information on the interaction of employment and population growth. A separation of retirement migration from employment-related migration also could not be implemented because of unavailable data.

Interactions between the demographic and economic parts of the model appear in both directions. The impact of employment growth on population growth occurs through economic variables lagged by one year (mainly local and national unemployment rates) with the intervening current variables being two employment change variables (in the manufacturing and the construction sectors). In the reverse direction, a current or lagged population variable (level or change) affects most sectoral employment variables to generally express a mixed demand/supply situation.

Secondary feedback effects from the population part to the employment part are taken care of through per capita income 
(i.e., an additional demand effect), a variable determined from population and employment changes and the unemployment rate.

The model consists of 25 equations, 11 of which are identities (Tables 4 and 5). The model was fitted to Tucson data for the period 1957-1975 using 2SLS estimation with a built-in correction for first-order correlation. The regression equations thus obtained (see Appendix B) display high coefficients of determination, the lowest values being observed in the cases of the unemployment rate and net migration equations $\left(R^{2}=.926\right.$ and .939 , respectively).

Table 4. Structure of the demometric model: regression equations and identities.

Regression Equations

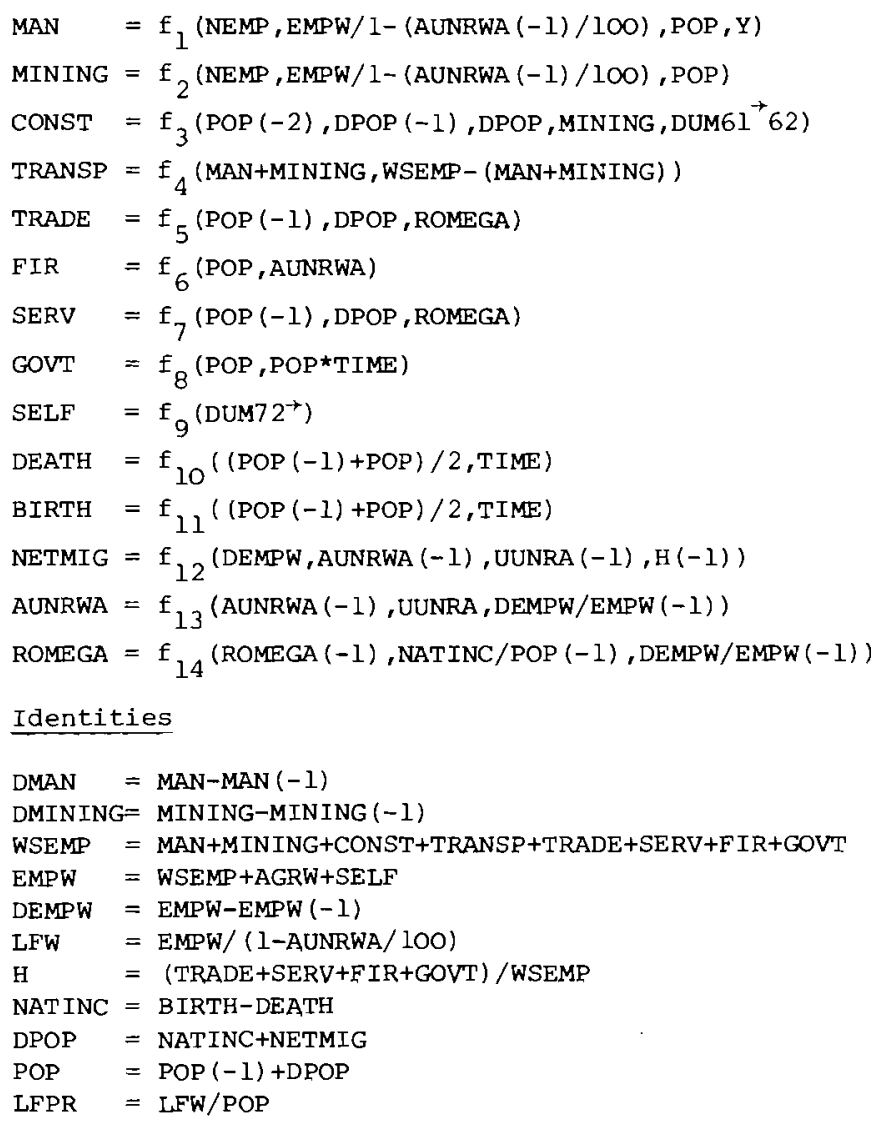

$\mathrm{LFPR}=\mathrm{LFW} / \mathrm{POP}$ 
Table 5. Variables in the demometric model.*

\section{Endogenous Variables (Local)}

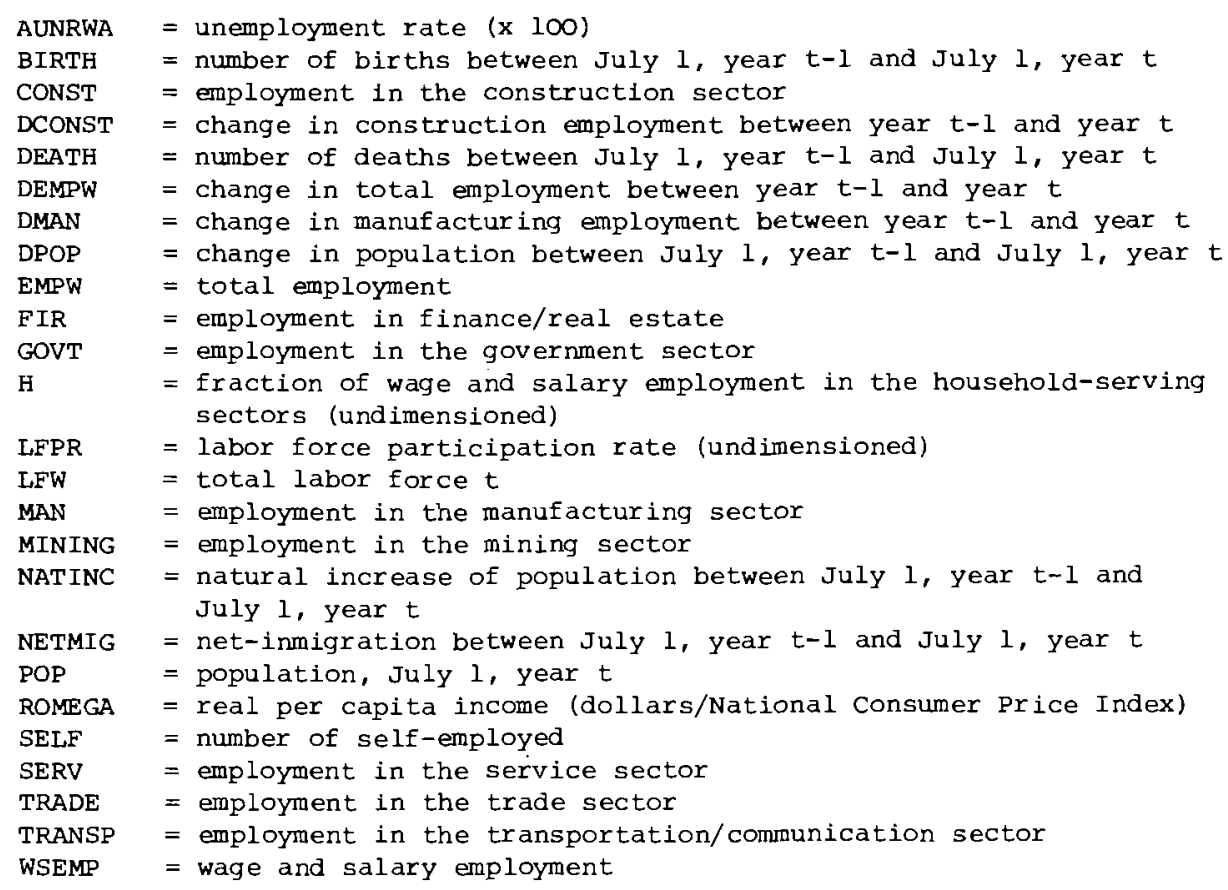

\section{Exogenous Variables}

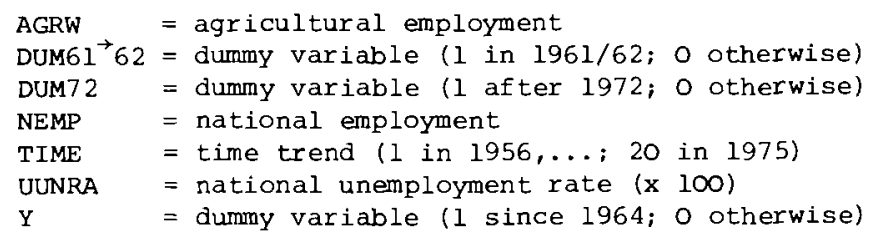

*All variables are expressed in thousands unless otherwise indicated. 
A frequently used indicator to measure the performance of the individual equations is the ratio of the standard error of the estimation to the mean of the dependent variable. Table B1 in Appendix 2 indicates that standard errors are less than five percent of the mean of the dependent variable. The only exception occurs with the net migration variable.

As its equations indicate, this model displays numerous nonlinearities, a feature that normally makes use of an iterative method (Gauss/Seidel) necessary for the simulation stage. However, as in the modified economic base model in the preceding section, the interaction between the variables of the model has been specified in a way that maintains linearity in the simultaneous links. Nonlinearities occur only in the delayed links. This permits a derivation of the final form of the model (although only with tedious analytical calculations) that leads to an easy simulation of the model.

Ex-post forecasts were developed with this model to test its ability to replicate the past growth of Tucson. In addition, mean absolute percent errors (MAPEs) which give an indication of the magnitude between the ex-post forecasts obtained and the corresponding actual values have been computed for each endogenous variable. As shown in Table 6, low MAPEs were obtained for all variables except for net migration, unemployment, and employment

Table 6. Evaluation of the ex-post forecasting ability of the demometric model.

$\begin{array}{lr}\text { Variable } & \text { Mean Absolute Percent } \\ & \\ \text { DEATH } & 1.89 \\ \text { BIRTH } & 2.66 \\ \text { NETMIG } & 32.25 \\ \text { POP } & 1.47 \\ \text { LFW } & 2.01 \\ \text { LFPR } & 1.32 \\ \text { WSEMP } & 1.17 \\ \text { EMPW } & 1.88 \\ \text { AUNRWA } & 9.70 \\ \text { ROMEGA } & 1.73 \\ \text { SELF } & 1.68 \\ \text { MINING } & 4.85 \\ \text { MAN } & 4.32 \\ \text { CONST } & 9.00 \\ \text { TRANS } & 3.27 \\ \text { TRADE } & 3.28 \\ \text { FIR } & 2.84 \\ \text { SERV } & 2.98 \\ \text { GOVT } & 5.57\end{array}$


in the construction sector. These are precisely the most volatile elements of Tucson's economy. However, a graphical comparison of the ex-post forecasts with the actual data relating to these variables in Figures 3 and 4 reveals that the model structure is adequate in its ability to replicate the annual variations of net migration and the unemployment rate.

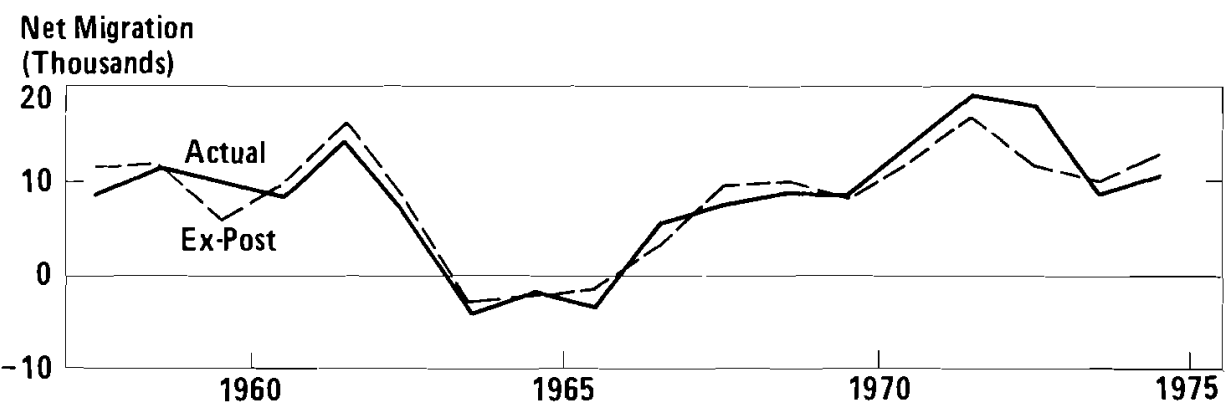

Figure 3. Demometric model of the Tucson SMSA: ex-post forecasts of net-migration compared to actual figures.

\section{Unemployment Rate}

\section{(Percentage)}

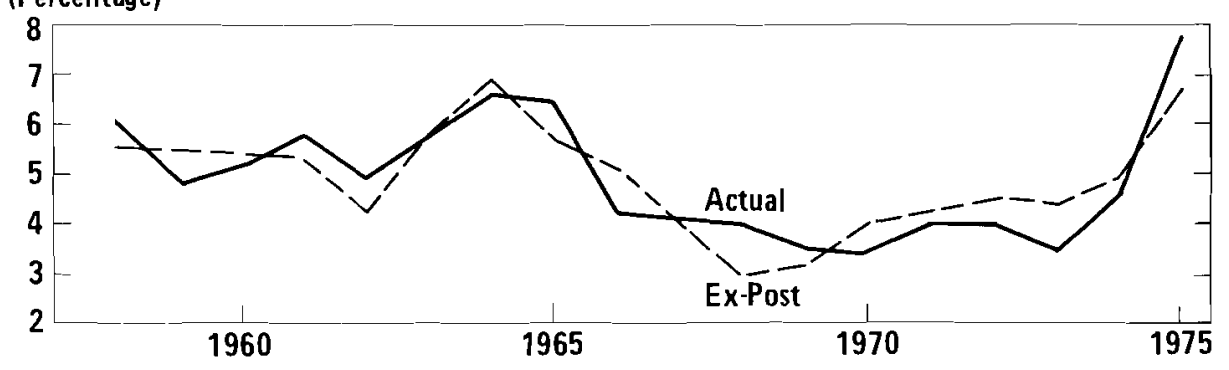

Figure 4. Demometric mode] of the Tucson SMSA: ex-post forecasts of the local unemployment rate compared to actual figures. 
Impact and Dynamic Multipliers Obtained with the Demometric Model

Table 7 summarizes the impact and dynamic multipliers resulting from exogenous increases in employment in the various sectors of Tucson's local economy in 1958 and 1976. These suggest the following observations.

- A given exogenous increase of employment has the largest consequences on local development if it occurs in the mining sector. An expansion of mining employment by 1000 workers in 1976 leads to an increase in total employment of 5140 workers in 1978 and an increase in population of 7230 by the same year.

- Exogenous employment expansions in the manufacturing and construction sectors also affect the growth of Tucson, but not as much as employment expansion in mining. The 1978 employment and population dynamic multipliers (for an exogenous increase taking place in 1976) are 3.62 and 5.95, respectively, for job creation in manufacturing, and 3.39 and 5.95, respectively, for job creation in construction (in contrast to 5.14 and 7.23 , respectively, for mining).

- Exogenous employment expansions in all other sectors have much lower consequences for the local economy. They are quite similar in all household-serving sectors (trade, finance and real estate, services and government). Threeyear dynamic employment and population multipliers for job creation in any of these sectors are, respectively, 2.46 and 2.61, and are only slightly higher for an initial expansion in the transportation/communication sector: 2.68 and 3.11 , respectively.

- In all cases, exogenous job creation sharply decreases the unemployment rate and increases the LFP rate in the year of occurrence, $T$. As time goes on, the effect on the unemployment rate tends to disappear, especially around years $\mathrm{T}+2$ and $\mathrm{T}+3$; the labor force participation rate tends to stabilize.* Once again the magnitude of the multiplier varies by sectors in mining, manufacturing, and construction.

- Finally, comparing the values of the multipliers for different years of job creation (see Table 7), we observe that: (a) impact multipliers have a slight tendency to

\footnotetext{
* As in the case of the modified economic base model of the preceding section, the unemployment rate multipliers display the same tendency toward instability when additional job creation relates to the early part of the sample period.
} 
decrease as job creation is delayed, * and (b) as in the modified economic base model, the dynamic multipliers have a tendency to decline as job creation is retarded. In the present case, this tendency is even more pronounced.**

Table 7. Impact and dynamic multipliers from the disaggregate demometric model. $\dagger$

$\begin{array}{ccccc}\text { Impact } & \text { Dynamic Multipliers For Year } \\ \text { Multiplier } & T+1 & T+2 & T+3 & T+4\end{array}$

Employment

\begin{tabular}{|c|c|c|c|c|c|}
\hline Mining & $4.95 / 4.37$ & $7.90 / 4.98$ & $9.37 / 5.14$ & $8.46 / 4.92$ & $6.43 / 4.83$ \\
\hline Manufacturing & $3.77 / 3.40$ & $5.76 / 3.71$ & $6.50 / 3.62$ & $5.67 / 3.44$ & $4.21 / 3.38$ \\
\hline Construction & $3.66 / 3.33$ & $5.52 / 3.56$ & $6.12 / 3.39$ & $5.26 / 3.21$ & $3.83 / 3.16$ \\
\hline Trade & $2.36 / 2.03$ & $3.62 / 2.32$ & $4.23 / 2.46$ & $3.69 / 2.31$ & $2.67 / 2.21$ \\
\hline \multicolumn{6}{|l|}{ Net-Migration } \\
\hline Mining & $2.88 / 2.76$ & $7.82 / 2.83$ & $6.36 / 1.32$ & $2.63 / .41$ & $-1.72 / .12$ \\
\hline Manufacturing & $2.97 / 2.89$ & $5.71 / 2.04$ & $4.18 / .72$ & $1.32 / .16$ & $-1.55 / .03$ \\
\hline Construction & $3.20 / 3.13$ & $5.47 / 1.93$ & $3.87 / .59$ & $1.09 / .09$ & $-1.63 / .00$ \\
\hline Trade & $.78 / .69$ & $3.34 / 1.44$ & $2.57 / .60$ & $.79 / .09$ & $-1.17 /-.09$ \\
\hline \multicolumn{6}{|l|}{ Population } \\
\hline Mining & $2.93 / 2.79$ & $10.94 / 5.74$ & $17.68 / 7.23$ & $20.82 / 7.84$ & $19.64 / 8.18$ \\
\hline Manufacturing & $3.01 / 2.93$ & $8.88 / 5.08$ & $13.36 / 5.95$ & $15.06 / 6.27$ & $13.89 / 6.47$ \\
\hline Construction & $3.24 / 3.17$ & $8.87 / 5.22$ & $13.03 / 5.95$ & $14.49 / 6.20$ & $13.22 / 6.38$ \\
\hline Trade & $.79 / .70$ & $4.20 / 1.95$ & $6.92 / 2.61$ & $7.90 / 2.78$ & $6.93 / 2.76$ \\
\hline
\end{tabular}

TThis table shows impact and dynamic multiplier effects on the main variables (employment, net-migration, unemployment rate and labor force participation rate) from job creation in mining, manufacturing, construction, and trade. Figures separated by a slash sign relate to multiplier effects generated by job creation in 1958 and 1976, respectively.

* This slightly diminishing tendency contrasts with the constancy of impact multipliers in the aggregate model. Note that the cause of this difference lies in the different treatment of simultaneous links: although simultaneous links are expressed by means of linear equations in both models, the coefficients are constant in the modified economic base model, but they depend on lagged variables in the demometric model.

**This larger diminishing tendency is the result of the larger importance accorded to the lag structure. 
Table 7. (cont'd)

$$
\begin{array}{ccccc} 
& & \text { Dynamic Multipliers For Year } \\
\text { Impact } & \mathrm{T}+1 & \mathrm{~T}+2 & \mathrm{~T}+3 & \mathrm{~T}+4 \\
\text { Multiplier } & & & &
\end{array}
$$

Unemployment Rate

\begin{tabular}{lrrrrr}
\hline Mining & $-1.19 /-.50$ & $-1.14 /-.26-.73 /-.12$ & $.50 /-.02$ & $.57 / .01$ \\
Manufacturing & $-.91 /-.39$ & $-.80 /-.19-.44 /-.06$ & $.09 / .00$ & $.42 / .01$ \\
Construction & $-.88 /-.38$ & $-.77 /-.18-.40 /-.05$ & $.11 / .00$ & $.42 / .01$ \\
Trade & $-.57 /-.23$ & $-.51 /-.12-.31 /-.06$ & $.05 /-.08$ & $.28 / .01$ \\
Labor Force & & & & & \\
Participation & & & & & \\
Ratex 10 & & & & & \\
Mining & $1.35 / .58$ & $1.49 / .56$ & $1.32 / .52$ & $.75 / .45$ & $.28 / .40$ \\
Manufacturing & $.91 / .39$ & $.97 / .35$ & $.79 / .35$ & $.39 / .26$ & $.08 / .22$ \\
Construction & $.85 / .35$ & $.89 / .31$ & $.71 / .31$ & $.32 / .21$ & $.27 / .18$ \\
Trade & $.72 / .32$ & $.78 / .32$ & $.72 / .32$ & $.47 / .29$ & $.26 / .27$
\end{tabular}

Besides the above considerations suggested by the data set out in Table 7 , an interesting question arises from their comparison with the multipliers obtained with the modified economic base model. Broadly speaking, tendencies displayed by the multipliers of both models are similar. This is to be expected since the structure of the demometric model is an immediate extension of that of the modified economic base model. Possibly, the disaggregated model leads to smaller impact effects and much larger dynamic effects because of an improved lag structure.

\section{CONCLUSION}

This paper has argued that the use of demometric methods would improve the quality and accuracy of multiplier analyses for rapidly growing areas.

First, it was shown that one of the most widely used tools for constructing such analyses--namely the traditional economic base model--presents serious limitations that makes its utilization undesirable in the case of such areas. They include:

- A heavy reliance on a demand view of regional growth, ignoring the role of households as suppliers of labor: 
- A quasi-static formulation of the regional growth process;

- An identification and measurement of the basic sector, not applicable to rapidly growing urban economies.

Secondly, it was made clear that if the economic base model was modified to accord a higher importance to demographic factors (introduction of migration as a dynamic factor, explicit consideration of labor force and unemployment variables, demographic revision of the measurement of the basic sector), it could lead to the derivation of more reliable impact and dynamic multipliers.

Thirdly, it was demonstrated that it is possible to bypass a division into basic and nonbasic employment sectors by implementing an analysis having an economic base flavor, but also a more general application of the demometric philosophy--one that allows for the construction and application of a disaggregate model from which impact and dynamic multipliers useful to policymakers of rapidly growing regions can be obtained.

To summarize, the peculiarities of rapidly growing areas do not readily permit the use of simple multiplier analyses based on the traditional economic base model. These areas call for additional resources to obtain meaningful multipliers. The two models proposed in this paper: the modified economic base model and the demometric model require the same data and approximately similar resources. Since the disaggregate demometric model yields more and better information for the same investment of resources, this suggests that ceteris paribus, a demometric model constitutes a more desirable alternative than a somewhat amended version of the economic base model. 


\author{
Appendix 1 \\ An Overview of Tucson's Development (1950-1975)
}

\title{
Population
}

The population of Pima County has experienced rapid growth over the last twenty-five years, increasing from a total of 141,500 in 1950 to 449,000 in 1975 (see Table A1). Its growth was rapid during the 1950 s but diminished significantly during the 19605 (a stabilization of the population was registered between 1963 and 1966). A sudden acceleration occurred in the early 1970 s and was maintained well into the economic recession that followed the 1973 oil crisis.

Table A1. Components of population change: Tucson SMSA 1950 to 1975 by quinquennial periods (in thousands).

Source: Derived by the author from annual population estimates

made by the Arizona Department of Economic Security,

1976; annual vital statistics data provided by the

Arizona Department of Health, 1976.

\begin{tabular}{|c|c|c|c|c|c|c|c|c|c|c|}
\hline \multirow[b]{2}{*}{ Period } & \multirow{2}{*}{$\begin{array}{l}\text { Pop. at } \\
\text { begin- } \\
\text { ning of } \\
\text { Period }\end{array}$} & \multicolumn{2}{|c|}{ Births } & \multicolumn{2}{|c|}{ Deaths } & \multicolumn{2}{|c|}{$\begin{array}{l}\text { Natural } \\
\text { Increase }\end{array}$} & \multicolumn{2}{|c|}{$\begin{array}{c}\text { Net } \\
\text { Migration }\end{array}$} & \multirow{2}{*}{$\begin{array}{l}\text { Pop. at } \\
\text { end of } \\
\text { Period }\end{array}$} \\
\hline & & $\begin{array}{l}\text { Num- } \\
\text { ber }\end{array}$ & $\begin{array}{c}\text { Rate } \\
: \%\end{array}$ & $\begin{array}{l}\text { Num- } \\
\text { ber }\end{array}$ & $\begin{array}{c}\text { Rate } \\
8\end{array}$ & $\begin{array}{l}\text { Num- } \\
\text { ber }\end{array}$ & $\begin{array}{c}\text { Rate } \\
\text { o }\end{array}$ & $\begin{array}{l}\text { Num- } \\
\text { ber }\end{array}$ & $\begin{array}{c}\text { Rate } \\
\frac{g}{\delta}\end{array}$ & \\
\hline $950-1955$ & 144.0 & 25.2 & 17.5 & 7.0 & 4.9 & 18.2 & 12.6 & 42.8 & 29.7 & 205.0 \\
\hline $955-1960$ & 205.0 & 32.1 & 15.7 & 9.2 & 4.5 & 22.9 & 11.2 & 41.1 & 20.1 & 269.0 \\
\hline $1960-1965$ & 269.0 & 34.3 & 12.7 & 11.7 & 4.3 & 22.6 & 8.4 & 22.1 & 8.2 & 313.7 \\
\hline $965-1970$ & 313.7 & 28.7 & 9.3 & 13.8 & 4.5 & 14.9 & 4.8 & 26.4 & 8.3 & 355.0 \\
\hline $370-1975$ & 355.0 & 35.0 & 9.9 & 16.5 & 4.7 & 18.5 & 5.2 & 67.7 & 19.1 & 441.2 \\
\hline
\end{tabular}

A large part of this population expansion results from net inmigration which accounts for roughly two-thirds of the population change over the last 25 years (see Table A1 and Figure A1). Indeed, because of its climate, Tucson attracts many retirees and workers in the older age groups. This has contributed to a continuous aging of its population. Nevertheless in 1975, the percentage of local population aged 65 and over was still slightly less than its national counterpart (see Table A2).

The reason for this perhaps surprising fact lies in that the continuous flow of retirement to Arizona and its metropolitan areas has been accompanied by a large flow of employment-related net inmigration, especially during the early 1970s (see Table A3). 


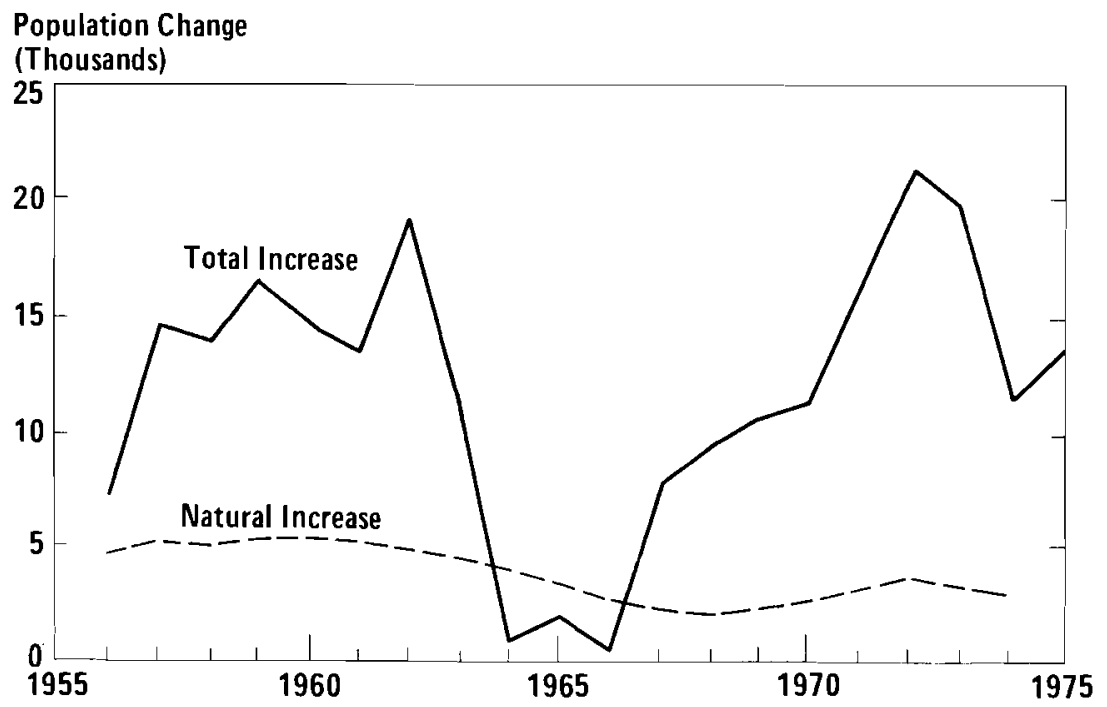

Figure A1. Components of population change: Tucson SMSA 1956 to 1975.

Source: Derived by author from Tucson vilal statistics (Arizona Health Department, 1976): population estimates (Department of Economic Security, 1976); U.S. Bureau of the Census (1973. 1976b).

Table A2. Age/sex composition of the population of Tucson SMSA and the United States: 1960, $1970,1975$.

\begin{tabular}{|c|c|c|c|c|c|c|c|c|c|c|c|c|}
\hline \multirow[t]{3}{*}{ Source } & \multicolumn{12}{|c|}{$\begin{array}{l}\text { Computed by author from data of the US Bureau of } \\
\text { the Census (1963a, 1963b, 1972a, 1972b, 1976a); } \\
\text { special } 1975 \text { census for Tucson SMSA. }\end{array}$} \\
\hline & \multicolumn{4}{|c|}{1960} & \multicolumn{4}{|c|}{1970} & \multicolumn{4}{|c|}{1975} \\
\hline & \multicolumn{2}{|c|}{ Tucson } & \multicolumn{2}{|c|}{ USA } & \multicolumn{2}{|c|}{ Tucson } & \multicolumn{2}{|c|}{ USA } & \multicolumn{2}{|c|}{ Tucson } & \multicolumn{2}{|c|}{ USA } \\
\hline Age & $\mathrm{M}$ & $F$ & M & $F$ & M & $F$ & M & $F$ & M & F & M & $F$ \\
\hline $0-14$ & 16.71 & 16.14 & 15.84 & 15.27 & 14.32 & 13.94 & 14.54 & 14.02 & 12.42 & 11.81 & 12.85 & 12.24 \\
\hline $15-24$ & 7.57 & 7.36 & 6.69 & 6.75 & 9.60 & 9.29 & 8.59 & 8.75 & 10.68 & 10.48 & 9.43 & 9.33 \\
\hline $25-44$ & 12.86 & 13.36 & 12.78 & 13.37 & 11.13 & 11.63 & 11.53 & 12.08 & 13.05 & 12.75 & 12.33 & 12.83 \\
\hline $45-64$ & 8.91 & 9.68 & 9.88 & 10.38 & 9.24 & 10.70 & 9.85 & 10.75 & 8.83 & 9.89 & 9.77 & 10.66 \\
\hline $5+$ & 3.55 & 3.86 & 4.07 & 4.97 & 4.52 & 5.63 & 4.15 & 5.74 & 4.47 & 5.62 & 4.30 & 6.26 \\
\hline
\end{tabular}


Table A3. Net population gains in selected age cohorts over three recent five-year periods, Tucson SMSA 1955-1960, 1965-1970, 1970-1975.

Source: Derived by the author from data of the us census of 1960,1970 and the 1975 spectal census for Tucson SMSA.

\begin{tabular}{|c|c|c|c|c|c|c|c|c|}
\hline \multirow[b]{3}{*}{ Period } & \multicolumn{8}{|c|}{ Cohort } \\
\hline & \multicolumn{2}{|c|}{$25-29$} & \multicolumn{2}{|c|}{$30-34$} & \multicolumn{2}{|c|}{$35-39$} & \multicolumn{2}{|c|}{$40-44$} \\
\hline & M & $F$ & M & $F$ & M & $\mathbf{F}$ & M & $F$ \\
\hline $1955-1960$ & -468 & 617 & 1178 & 1886 & 1315 & 1304 & 940 & 1060 \\
\hline $1965-1970$ & -761 & 15 & 101 & 391 & 631 & 312 & 205 & 494 \\
\hline $1970-1975$ & 4625 & 4141 & 2926 & 2758 & 2274 & 2067 & 2164 & 1908 \\
\hline
\end{tabular}

\section{Employment}

From an economic point of view, Tucson's rapid population growth has been paralleled by a rapid growth of local activities, thus tilting its employment structure away from the primary sector (see Table A4).

\section{Table A4. Labor force and employment figures Tucson SMSA 1956-1975.}

Source: Unpublished data from Arizona Department of Economic Security.

$$
\begin{gathered}
\text { Labor Force } \\
\text { (in thousands) } \\
\text { by place of }
\end{gathered}
$$

Year work Residence

195

1957

1958

1959

1960

1961

1962

1963

1964

1965

1966

1967

1968

1969

1970

1971

1972

1973

1974

1975

$$
\begin{gathered}
\text { Unemployment } \\
\text { Rate by } \\
\text { place of }(z)
\end{gathered}
$$

Work Residence

3.7

4.1

6.0

4. 8

5.1

5.7

4.9

5.8

6.5

6.3

4.2

4.0

4.0

3.3

3.4

4.0

3.8

$-$

$-$

$-$

$-$

$-$

$-$

$-$

-

$-$

6.7

6.5

4.5

4.4

4.4

3.5

3.5

4.1

4.0

Employment
Total
(in thousands)
by place of
Work Residence

3.4

4.6

8.0
68.4

72.9

74.5

80.1

83.4

87.1

94.2

92.8

90.0

89.0

94.5

98.5

101.8

110.1

116.7

125.0

138.0

$-$

$-$
Agricul tural Employment (in thousands) by place of work Residence

$\begin{array}{rcl}- & 3.1 & - \\ - & 2.5 & - \\ - & 2.6 & - \\ - & 2.3 & - \\ - & 2.2 & - \\ - & 2.0 & - \\ - & 1.9 & - \\ - & 1.8 & - \\ 90.5 & 1.8 & 1.5 \\ 91.0 & 1.7 & 1.3 \\ 96.2 & 1.7 & 1.3 \\ 99.8 & 1.8 & 1.4 \\ 103.1 & 1.7 & 1.3 \\ 110.6 & 1.8 & 1.3 \\ 117.8 & 1.8 & 1.9 \\ 127.4 & 1.6 & 1.8 \\ 142.2 & 1.6 & 1.8 \\ 153.3 & - & 1.8 \\ 157.0 & - & 1.6 \\ 155.4 & - & 1.7\end{array}$


Table A4: (cont'd)

\begin{tabular}{|c|c|c|c|c|c|c|c|c|c|}
\hline \multirow[b]{2}{*}{ Total } & \multicolumn{9}{|c|}{$\begin{array}{r}\text { Employment (in thousands) } \\
\text { wage and Salary* }\end{array}$} \\
\hline & $\begin{array}{l}\text { Manu- } \\
\text { fac- } \\
\text { turing }\end{array}$ & Mining & $\begin{array}{l}\text { Con- } \\
\text { struc- } \\
\text { tion }\end{array}$ & $\begin{array}{l}\text { Trans- } \\
\text { porta- } \\
\text { tion }\end{array}$ & Trade & FIRE & $\begin{array}{l}\text { Ser- } \\
\text { vices }\end{array}$ & $\begin{array}{l}\text { Govern- } \\
\text { ment }\end{array}$ & other $\star \star$ \\
\hline 54.4 & 9.7 & 2.1 & 4.7 & 5.3 & 12.2 & 1.8 & 8.2 & 10.4 & 10.9 \\
\hline 59.1 & 9.9 & 2.4 & 5.4 & 5.3 & 13.2 & 2.1 & 9.1 & 11.7 & 11.3 \\
\hline 60.5 & 8.9 & 2.3 & 5.6 & 5.1 & 13.6 & 2.4 & 10.0 & 12.6 & 11.4 \\
\hline 66.0 & 9.2 & 2.6 & 6.9 & 5.2 & 14.8 & 2.6 & 11.0 & 13.7 & 11.8 \\
\hline 69.2 & 8.4 & 2.9 & 6.9 & 5.2 & 15.8 & 2.9 & 12.2 & 14.9 & 12.0 \\
\hline 72.8 & 8.4 & 3.1 & 7.8 & 5.1 & 16.3 & 3.1 & 12.9 & 16.1 & 12.3 \\
\hline 79.5 & 9.2 & 3.4 & 9.8 & 5.3 & 17.3 & 3.4 & 13.6 & 17.5 & 12.8 \\
\hline 78.3 & 9.3 & 3.2 & 6.5 & 5.4 & 17.4 & 3.7 & 13.9 & 18.9 & 12.7 \\
\hline 75.7 & 6.6 & 3.3 & 5.9 & 5.3 & 17.1 & 3.8 & 13.9 & 19.8 & 12.5 \\
\hline 76.0 & 6.3 & 3.4 & 5.5 & 5.2 & 17.3 & 3.6 & 13.7 & 21.0 & 11.3 \\
\hline 81.7 & 7.7 & 4.0 & 5.6 & 5.1 & 18.1 & 3.5 & 14.6 & 23.1 & 11.1 \\
\hline 86.0 & 8.8 & 4.3 & 5.8 & 5.3 & 18.8 & 3.5 & 15.7 & 23.8 & 10.7 \\
\hline 89.7 & 7.8 & 4.7 & 7.0 & 5.3 & 19.6 & 3.7 & 16.7 & 24.9 & 10.4 \\
\hline 98.0 & 8.3 & 5.5 & 9.4 & 5.5 & 21.5 & 4.2 & 17.8 & 25.8 & 10.3 \\
\hline 104.8 & 9.0 & 6.5 & 8.5 & 5.9 & 23.7 & 5.0 & 19.3 & 26.9 & 10.1 \\
\hline 113.3 & 8.9 & 6.7 & 10.4 & 6.1 & 25.3 & 5.1 & 20.8 & 30.0 & 10.1 \\
\hline 127.3 & 10.4 & 7.0 & 12.3 & 6.9 & 28.4 & 5.9 & 23.0 & 33.4 & 13.1 \\
\hline 138.0 & 12.1 & 7.9 & 13.3 & 7.6 & 30.2 & 6.5 & 25.4 & 35.0 & 13.5 \\
\hline 142.0 & 12.2 & 8.5 & 11.6 & 8.0 & 30.1 & 6.5 & 26.7 & 38.4 & 13.4 \\
\hline 140.7 & 11.8 & 7.9 & 10.1 & 7.5 & 30.4 & 6.1 & 26.6 & 40.3 & 13.0 \\
\hline
\end{tabular}

Manufacturing was a relatively small proportion ( 8 percent) of total employment in 1974, a proportion which aside from Las Vegas is by far the smallest over the SMSA's in the 100,000200,000 employment range. Mining (copper extraction), on the other hand, although consisting of operations accounting for a large part of the national activity in this sector, employs a relatively small part of Tucson's workforce (up to 8500 workers in 1974 ).

The construction sector, employing up to 10 percent of the workforce, is comparatively large in Tucson as a consequence of the continuous population growth, but most of the Tucson workforce is engaged in local activities, such as services (17.1 percent), trade ( 19.5 percent) and government $(25.1$ percent), all percentages relating to 1975 . 
Labor Force and Unemployment

Over the last quarter of the century, the growth of the labor force has more or less followed the growth of population. In the later years, however, it has shown a tendency to surpass the growth of population, thus leading to a significant increase in the labor force participation rate. Nevertheless, this rate remains lower than its national counterpart, possibly because the Tucson population includes a large proportion of students, military personnel, and people with spanish heritage.

It is also important to note that the local unemployment rate has generally been smaller than the national rate except in the middle 1960 s when, following important lay-offs in the manufacturing sector, economic development and population growth were slowed down. 

Appendix 2

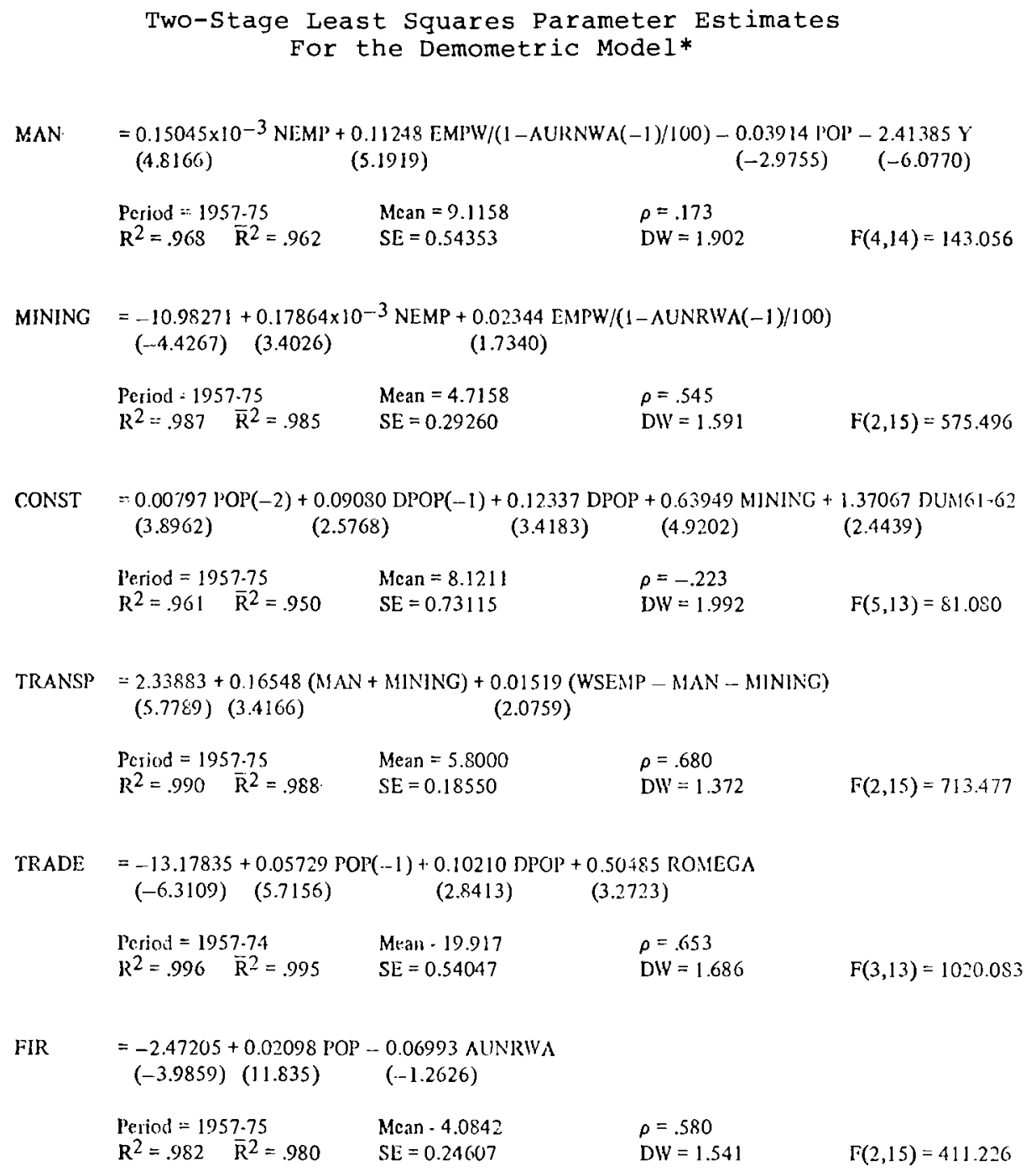

\footnotetext{
* The meaning of each included variable is explained in Table 5 . The various statistics attached to each equation are here reported with all the digits provided by the computer program used to perform these 2SLS regressions. Some of these statistics may not be significant.
} 


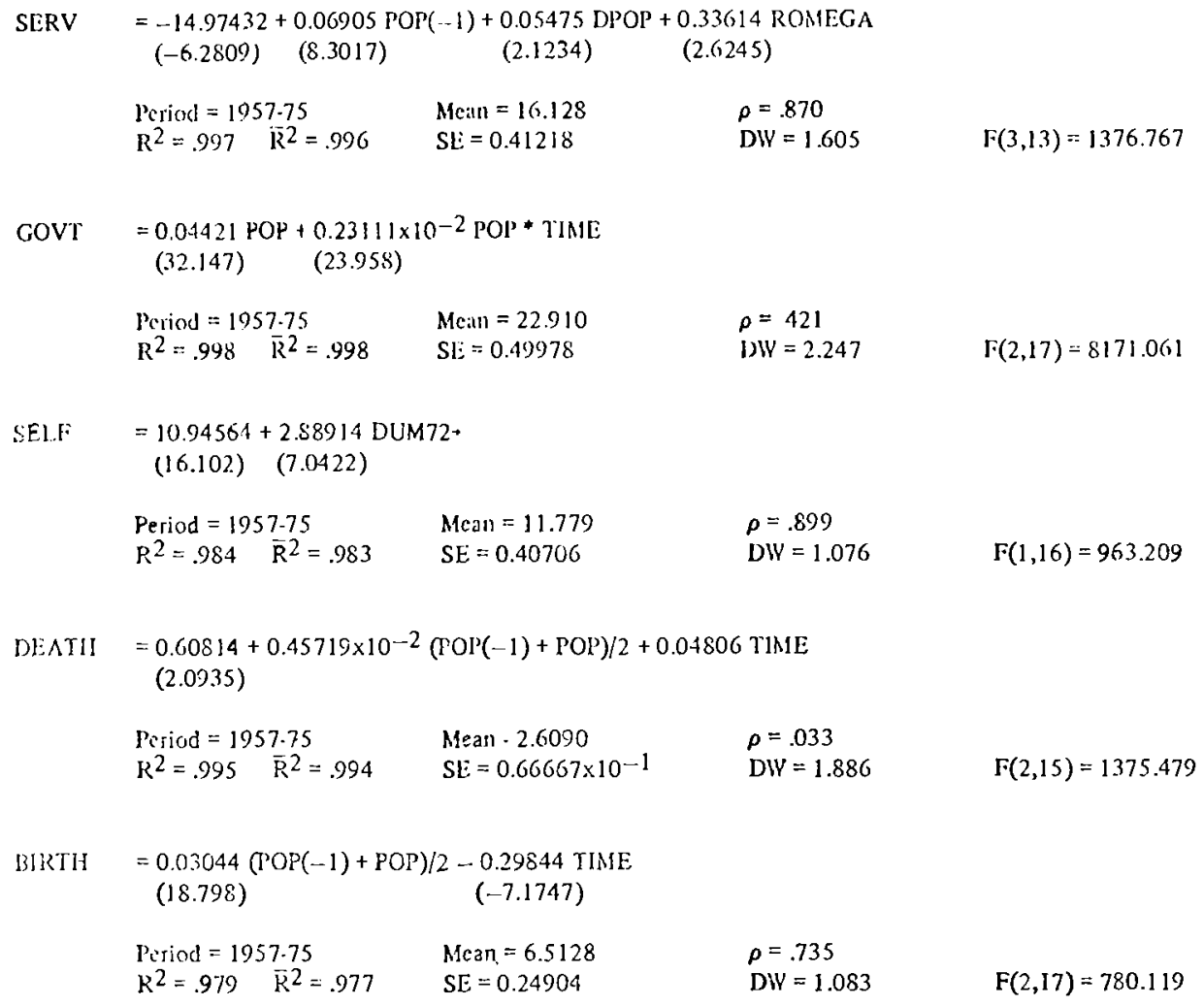




\section{REFERENCES}

Arizona Department of Economic Security (1976), Population Estimates of Arizona, report number 8, Phoenix.

Arizona State Department of Health (1976), unpublished Vital Statistics, Data Analysis Section, Health Records and Statistics Division, Phoenix.

Borts, Georges H. and J. Stein (1964), Economic Growth in a Free Market, Columbia University Press, New York.

Chang, Hui S. (1976), Tennessee Econometric Model: Phase I, Center for Business and Economic Research College of Business Administration, The University of Tennessee, Knoxville.

Czamanski, Stanislaw (1964), A Model of Urban Growth, Papers of the Regional Science Association, 13, 177-200.

Goldberger, A.S. (1959). Impact Multipliers and Dynamic Properties of Klein-Goldberger Model, North-Holland, Amsterdam.

Kalindaga, Y.K. (1974), Interdependence between Employment Growth and Interregional Migration: An Empirical Study of U.S. Metropolitan Areas, Ph.D dissertation, Northwestern University, Evanston, Illinois.

Greenwood, Michael T. (1973), Urban Economic Growth and Migration: Their Interaction, Environment and Planning, 5 , 91-112.

Mathur, V.K. and Harbey S. Rosen (1972), An Econometric Export Base Model: A New Technique, London Papers in Regional Science, $3,31-43$.

Mazek, Warren F. and John Chang (1972), The Chicken or Egg FowlUp in Migration: Comment, Southern Economic Journal, 34 , $1,133-142$.

Miron, John (1977), Job Search, Migration and Metropolitan Growth, RM-77-3, International Institute for Applied Systems Analysis, Laxenburg, Austria.

Monthly Labor Review (selected years) U.S. Department of Labor, Washington, D.C.

Muth, Richard F. (1971), Migration: Chicken or Egg?, Southern Economic Journal, 37, 295-305.

Olvey, Lee D. (1972), Regional Growth and Interregional Migration: Their Pattern of Interaction, Review of Regional Studies, 2, 139-63. 
Rogers, Andrei (1976a), Migration and Settlement, IIASA Conference 176, 2, 43-68, International Institute for Applied Systems Analysis, Laxenburg, Austria.

Rogers, Andrei (1976b), Demometries of Migration and Settlement, RM-76-68, International Institute for Applied Systems Analysis, Laxenburg, Austria.

U.S. Bureau of the Census (1963a), Census of Population 1960: Migration Between State Economic Areas, U.S. Government Printing office, Washington, D.C.

U.S. Bureau of the Census (1963b), Census of Population 1960, Vol. 1, Part 4, Arizona, U.S. Government Printing office, Washington D.C.

U.S. Bureau of the Census (1972a), Census of Population 1970: Arizona, General Population Characteristics, PC (1), 84 , U.S. Government Printing Office, Washington, D.C.

U.S. Bureau of the Census (1972b), Census of Population 1970: Migration Between State Economic Areas, PC (2)E, U.S. Government Printing office, Washington, D.C.

U.S. Bureau of the Census (1973), Estimates of the Population of Counties and Metropolitan Areas, Current Population Report, Series P-25, No. 520, U.S. Government Printing Office, Washington, D.C.

U.S. Bureau of the Census (1976a), unpublished data from the Special Census for Pima County, Arizona, October 20, 1975.

U.S. Bureau of the Census $(1976 \mathrm{~b})$, Estimation of the Population of Counties: July 1, 1973 and July 1, 1974, Current Population Reports, Series P-25, No. 620, U.S. Government Printing Office, Washington, D.C. 


\section{PAPERS OF THE MIGRATION AND SETTLEMENT STUDY}

\section{Papers in the Dynamics Series}

1. Andrei Rogers and Frans Willekens, Spatial Population Dynamics, RR-75-24, International Institute for Applied Systems Analysis, Laxenburg, Austria, 1975; published in Papers, Regional Science Association, 36 (1976), 3-34.

2. Andrei Rogers and Jacques Ledent, Multiregional Population Projection, internal working paper, International Institute for Applied Systems Analysis, Laxenburg, Austria; published by Jean Cea, ed., Optimization Techniques: Modelling and Optimization in the Service of Man, Part 1, Springer Verlag, Berlin, 1976, pp. 31-58.

3. Andrei Rogers and Jacques Ledent, Increment-Decrement Life Tables: A Comment, internal working paper, International Institute for Applied Systems Analysis, Laxenburg, Austria; published in Demography, $13(1976), 287-290$.

4. Andrei Rogers, Spatial Migration Expectancies, RM-75-57, International Institute for Applied Systems Analysis, Laxenburg, Austria, 1975.

5. Andrei Rogers, Aggregation and Decomposition in Population Projection, RM-76-11, International Institute for Applied Systems Analysis, Laxenburg, Austria; published in revised form in Environment and Planning $A, \underline{8}(1976)$, 515-541.

6. Andrei Rogers and Luis J. Castro, Model Multiregional Life Tables and Stable Populations, RR-76-09, International Institute for Applied Systems Analysis, Laxenburg, Austria, 1976.

7. Andrei Rogers and Frans Willekens, Spatial Zero PopuLation Growth, RM-76-25, International Institute for Applied Systems Analysis, Laxenburg, Austria, 1976.

8. Frans Willekens, Sensitivity Analysis, RM-76-49, International Institute for Applied Systems Analysis, Laxenburg, Austria, 1976; published in revised form in Environment and Planning A, 9 (1977), 653-674. 
9. Andrei Rogers and Frans Willekens, The Spatial Reproductive Value and the Spatial Momentum of Zero Population Growth, RM-76-81, International Institute for Applied Systems Analysis, Laxenburg, Austria, 1976.

10. Frans Willekens, The Spatial Reproductive Value: Theory and Applications, RM-77-09, International Institute for Applied Systems Analysis, Laxenburg, Austria, 1977.

11. Michael A. Stoto, on the Relationship of Childhood to Labor Force Migration Rates, RM-77-55, International Institute for Applied Systems Analysis, Laxenburg, Austria, 1977.

12. Jacques Ledent, Intrinsic Rates and Stable Age-Specific Mortality (and Migration) Rates of the Growth Matrix operator in the Single Region (Multiregion) Population Model, RM-77-37, International Institute for Applied Systems Analysis, Laxenburg, Austria, 1977.

13. Andrei Rogers, Richard Raquillet and Luis J. Castro, Model Migration Schedules and their Applications, RM-77-57, International Institute for Applied Systems Analysis, Laxenburg, Austria, 1977.

\section{Papers in the Demometrics Series}

1. Andrei Rogers, Demometrics of Migration and Settlement, RM-76-68, International Institute for Applied Systems Analysis, Laxenburg, Austria, 1976; forthcoming in Papers of the Regional Science Association, British Section, Pion Ltd., London.

2. John Miron, Job-Search, Migration and Metropolitan Growth, RM-77-03, International Institute for Applied Systems Analysis, Laxenburg, Austria, 1977.

3. Jacques Ledent, Regional Multiplier Analysis: A Demometric Approach, RR-78-03, International Institute for Applied Systems Analysis, Laxenburg, Austria (forthcoming).

\section{Papers in the Policy Analysis Series}

1. Yuri Evtushenko and Ross D. Mackinnon, Non-Linear Programming Approaches to National Settlement System planning, RR-75-26, International Institute for Applied Systems Analysis, Laxenburg, Austria 1975; published in revised form in Environment and planning $A, 8$ (1976), 637-653. 
2. R.K. Mehra, An Optimal Control Approach to National Settlement System Planning, RM-75-58, International Institute for Applied Systems Analysis, Laxenburg, Austria, 1975.

3. Frans Willekens, Optimal Migration Policies, RM-76-50, International Institute for Applied systems Analysis, Laxenburg, Austria, 1976.

4. Anatoli Propoi and Frans Willekens, A Dynamic Linear Programing Approach to National Settlement System Planning, RM-77-08, International Institute for Applied Systems Analysis, Laxenburg, Austria, 1977.

5. Frans Willekens and Andrei Rogers, Normative Modeling in Demo-Economics, RR-77-23, International Institute for Applied Systems Analysis, Laxenburg, Austria, 1977.

1. Ross D. Mackinnon and Anna Maria Skarke, Exploratory Analyses of the 1966-1971 Austrian Migration Table, RR-75-31, International Institute for Applied Systems Analysis, Laxenburg, Austria, 1975; published in revised form in Regional Studies, 11 (1977), 99-111.

2. Galina Kiseleva, The Influence of Urbanization on the Birthrate and Mortality Rate for Major Cities in the USSR, RM-75-68, International Institute for Applied Systems Analysis, Laxenburg, Austria, 1975.

3. George Demko, Soviet Population Policy, RM-75-74, International Institute for Applied systems Analysis, Laxenburg, Austria, 1975.

4. Andrei Rogers, The Comparative Migration and Settiement Study: A Summary of Workshop Proceedings and Conclusions, RM-76-01, International Institute for Applied Systems Analysis, Laxenburg, Austria, 1976.

5. Andrei Rogers, Two Methodological Notes on Spatial Population Dynamics in the Soviet Union, RM-76-48, International Institute for Applied Systems Analysis, Laxenburg, Austria, 1976. 
6. Frans Willekens and Andrei Rogers, Computer Programs for Spatial Demographic Analysis, RM-76-58, International Institute for Applied Systems Analysis, Laxenburg, Austria, 1976.

7. Frans Willekens and Andrei Rogers, More Computer Programs for Spatial Demographic Analysis, RM-77-30, International Institute for Applied Systems Analysis, Laxenburg, Austria, 1977.

8. Frans Willekens, The Recovery of Detailed Migration Patterns from Aggregate Data: An Entropy Maximizing Approach, RM-77-58, International Institute for Applied Systems Analysis, Laxenburg, Austria, 1977.

9. Frans Willekens, Demographic Analysis of Urban Growth: The Case of Brussels, International Institute for Applied Systems Analysis, Laxenburg, Austria (forthcoming).

\section{$V$ Related Papers of the Population, Resources and Growth Study}

1. Nathan Keyfitz, Understanding World Mode2s, RM-77-18, International Institute for Applied Systems Analysis, Laxenburg, Austria, 1977.

2. Andrei Rogers, Migration, Urbanization, Resources and Development, RR-77-14, International Institute for Applied Systems Analysis, Laxenburg, Austria, 1977.

3. Roman Kulikowski, Optimization of Rural-Urban Development and Migration, RM-77-41, International Institute for Applied Systems Analysis, Laxenburg, Austria, 1977.

4. Frans Willekens, Spatial Population Growth in Developing Countries: With a Special Emphasis on the Impact of Agriculture. International Institute for Applied Systems Analysis, Laxenburg; Austria (forthcoming). 